\title{
Procedure to Calibrate and Verify Numerical Models of ESTUARINE HYDRODYNAMICS
}

\author{
By Ming-Hsi Hsu, ${ }^{1}$ Albert Y. Kuo, ${ }^{2}$ Member, ASCE, Jan-Tai Kuo, ${ }^{3}$ Member, ASCE, \\ and Wen-Cheng Liu $^{4}$
}

\begin{abstract}
In most hydrodynamic models, friction and turbulent diffusion/dispersion coefficients are the important calibration parameters affecting the calculation of surface elevation, velocity and salinity distribution. This paper presents a rational approach to calibrate and verify a hydrodynamic model of partially stratified estuaries. The calibration procedures and verification requirements are demonstrated with the application of a vertical (laterally averaged) two-dimensional model to a branched estuarine river system. The friction coefficient is calibrated and verified with model simulation of barotropic flow, and the turbulent diffusion and dispersion coefficients are calibrated through comparison of salinity distributions. The overall model verification is suggested to be achieved with comparisons of Eulerian residual circulation and salinity distribution. In the case of the Tanshui River system, the available prototype current records are too short to calculate slowly varying residual currents. The snapshots of the model-computed and field-measured residual currents are provided to qualitatively agree with theoretical analysis. The overall performance of the model is verified with an additional set of salinity data.
\end{abstract}

\section{INTRODUCTION}

The estuary, together with the tidal freshwater river upstream of it, comprise a pathway for exchange of water and materials between a drainage basin and coastal region. To predict the fate and transport of materials from land to the ocean requires the knowledge of water movement through this stretch of water body. The hydrodynamic characteristics of estuaries have properties of riverine flow and coastal flow. The former includes seasonal and transient variations of freshwater discharge. The later is dominated by tide and is influenced by the saltwater-freshwater interaction as well as meteorological events. The flow in a particular estuary is further complicated by its irregular geometry and bathymetry. Numerical models are often resorted to in the study of water movement, or circulation, in estuaries and tidal rivers.

It is an accepted requirement that a numerical model of estuarine hydrodynamics be calibrated and verified before being put into any practical usage. However, there is no widely accepted procedure for carrying out these tasks. Model calibration appears in various forms, dependent on data availability, characteristics of water body, and most of all, the perceptions and opinions of modelers. It often happens that calibrated model results are compared with observed data to demonstrate "agreements," with little explanation of which coefficients were adjusted (and the nature of the adjustment) in arriving at the calibrated model.

Scatter plots comparing the computed and observed tidal ranges and phases of a single constituent tide have been used to calibrate the models; for example, Blumberg (1977) and Oey et al. (1985) used $M_{2}$ tide. Oey et al. (1985) also showed the comparison between the computed and observed time se-

${ }^{1}$ Prof., Dept. of Agric. Engrg., and Sr. Res. Fellow, Hydr. Res. Lab., Nat. Taiwan Univ., Taipei 10617, Taiwan, R.O.C.

${ }^{2}$ Prof., School of Marine Sci./Virginia Inst. of Marine Sci., Coll. of William and Mary, Gloucester Point, VA, and Visiting Res. Fellow, Hydr. Res. Lab., Nat. Taiwan Univ., Taipei 10617, Taiwan, R.O.C.

${ }^{3}$ Prof., Dept. of Civ. Engrg., and Sr. Res. Fellow, Hydr. Res. Lab., Nat. Taiwan Univ., Taipei 16017, Taiwan, R.O.C.

${ }^{4}$ Doctoral Student, Dept. of Agric. Engrg., and Res. Engrg., Hydr. Res. Lab., Nat. Taiwan Univ., Taipei 10617, Taiwan, R.O.C.

Note. Discussion open until July 1, 1999. To extend the closing date one month, a written request must be filed with the ASCE Manager of Journals. The manuscript for this paper was submitted for review and possible publication on July 3, 1997. This paper is part of the Journal of Hydraulic Engineering, Vol. 125, No. 2, February, 1999. CASCE, ISSN 0733-9429/99/0002-0166-0182/\$8.00 + \$.50 per page. Paper No. 15923. ries data of velocities at some stations to demonstrate the reasonableness of the model results, though they did not mention if this was part of the calibration process. Blumberg (1977) used tidal range and mean surface elevation as a function of distance from the estuarine mouth to calibrate a vertical twodimensional (2D) model of the Potomac River, in the United States. Park and Kuo (1993) calibrated their model by fitting the variations of tidal range and phase as the $M_{2}$ tide propagated upestuary. Muin and Spaulding (1996) concluded that tidal amplitude was not sensitive to the friction coefficient while applying their model to simulate the tidal circulation in the Providence River, R.I., in which the tide exhibited a cooscillating wave pattern. They determined the value of the friction coefficient by matching the tidal current amplitudes at selected stations with $M_{2}$ tide as a forcing function at the mouth of the river. They further compared the computed and observed tidal current amplitudes and phases with seven constituent tides as a forcing function.

A number of models were calibrated with time series data of surface elevation, velocity, and salinity at stations wherever they are available; for example, some of the models presented in the reports by the Waterway Experiment Station, U.S. Army Corps of Engineers. Chen and Lee (1991) calibrated their horizontal 2D model of the Great Lake river-estuary with 5-day time series data of water surface elevation and velocity at three stations each. Johnson et al. (1993) calibrated their three-dimensional (3D) model of the Chesapeake Bay with time series data of surface elevation, velocity, and salinity. They also compared the calculated and measured salinity distributions and the overall pattern of residual currents.

In a report of the ASCE Task Committee on Transport Prediction in Partially Stratified Tidal Water, Wang et al. (1990) addressed the subjects of model calibration and verification, among many other subjects. They recommend that a model be initially calibrated to surface elevations and currents of astronomical tides, followed by calibration of exchange processes and turbulence closures. Ditmars et al. (1987) also recommended testing the validity of an estuarine circulation model against current data as well as tidal height. Wang et al. (1990) further emphasized quantitative measures of model performance in comparison with prototype data; however, they did not propose any procedure for carrying out model calibration and verification.

This paper presents a rational approach to calibrate a hydrodynamic model of partially stratified estuaries. The calibration and verification procedures are demonstrated with the ap- 
plication of a vertical (laterally averaged) 2D model to a branched estuarine river system. The numerical scheme of the model has been tested with the analytical solution of cooscillating tide in a rectangular channel. This paper will deal mainly with the application of the model to a prototype estuary.

\section{MODEL DESCRIPTION}

A laterally integrated 2D, real-time model of estuarine hydrodynamics and water quality (Hydrodynamic Eutrophication Model, HEM-V2D) was developed by Park and Kuo (1993). The model is based on the principles of conservation of volume, momentum, and mass. The model is expanded to include the simulation of tributary-mainstem interaction, for application to the tidal portion of the Tanshui River system in northern Taiwan. The $2 \mathrm{D}$ branching model predicts the water surface elevation along the river and the longitudinal and vertical distributions of velocity, salinity, and concentrations of water quality variables and suspended sediment. Because the purpose of this paper is to present a procedure for calibration and verification of a numerical model, only the basic equations of the model and its treatment of the tributary junction are briefly described in the following section.

\section{Governing Equations}

In a right-handed Cartesian coordinate system, with the $x$ axis directed seaward and the $z$-axis directed upward, the equations for the hydrodynamic portion of the model are as follows:

laterally integrated continuity equation

$$
\frac{\partial(u B)}{\partial x}+\frac{\partial(w B)}{\partial z}=q_{p}
$$

sectionally integrated continuity equation

$$
\frac{\partial}{\partial t}\left(B_{\eta} \eta\right)+\frac{\partial}{\partial x} \int_{-H}^{\eta}(u B) d z=q
$$

laterally integrated momentum equation

$$
\begin{gathered}
\frac{\partial(u B)}{\partial t}+\frac{\partial(u B u)}{\partial x}+\frac{\partial(u B w)}{\partial z}=-\frac{B}{\rho} \frac{\partial p}{\partial x} \\
+\frac{\partial}{\partial x}\left(A_{x} B \frac{\partial u}{\partial x}\right)+\frac{\partial}{\partial z}\left(A_{z} B \frac{\partial u}{\partial z}\right)
\end{gathered}
$$

hydrostatic equation

$$
\frac{\partial p}{\partial z}=-\rho g
$$

laterally integrated mass balance equation for salt

$$
\begin{gathered}
\frac{\partial(s B)}{\partial x}+\frac{\partial(s B u)}{\partial x}+\frac{\partial(s B w)}{\partial z}=\frac{\partial}{\partial x}\left(K_{x} B \frac{\partial s}{\partial x}\right) \\
+\frac{\partial}{\partial z}\left(K_{z} B \frac{\partial s}{\partial z}\right)+S_{0}
\end{gathered}
$$

equation of state

$$
\rho=\rho_{0}(1+k s)
$$

where $x=$ distance seaward along river axis; $z=$ distance upward in vertical direction; $t=$ time; $q_{p}=$ lateral inflow per unit lateral area; $q=$ lateral inflow per unit river length; $\eta=$ position of the free surface above mean sea level; $s=$ laterally averaged salinity; $u$ and $w=$ laterally averaged velocities in the $x$ - and $z$-directions, respectively; $B=$ river width; $B_{\eta}=$ width at the free surface including side storage area; $H=$ total depth below mean sea level; $p=$ pressure; $g=$ gravitational acceleration; $A_{z}$ and $K_{z}=$ turbulent viscosity and diffusivity, respectively, in $z$-direction; $A_{x}$ and $K_{x}=$ dispersion coefficients for momentum and mass, respectively, in the $x$-direction; $\rho$ and $\rho_{0}=$ water density and freshwater density, respectively; $k=$ constant relating density to salinity $\left[=7.5 \times 10^{-4} /\right.$ parts per thousand (ppt)]; and $S_{0}=$ source and sink of salt due to exchange with side storage area.

Eqs. (1), (3), and (5) are integrated over a layer of finite thickness and then solved with (2), (4), and (6) by a two-time level, finite-difference scheme with spatially staggered grid. The implicit treatment of the vertical diffusion terms results in a tri-diagonal matrix in the vertical direction. To improve numerical stability, the pressure gradient term in (3) is evaluated using $\eta$ at a new time step. The method of the solution is detailed in Park and Kuo (1993, 1994); the remainder of this section explains the treatments of the interaction of tributaries and mainstem.

\section{Treatment of Free Surface Elevation at Junction}

At the junction of mainstem and tributary (Fig. 1), the finitedifference equation for free surface elevation, discretized from the continuity equation, is

$$
\begin{gathered}
\eta_{i, 2}=\eta_{i, 1}+\frac{\Delta t}{B_{i, 1}+S T B_{i}+B E J_{i, 1}}\left\{\left(\frac{B_{i, 1}+B_{i, 2}}{2}+B E J_{i, 1}\right)\right. \\
\left.\cdot w_{i, 1,1}-\frac{1}{\Delta x}\left(T M P_{i+1}-T M P_{i}-T M P B_{m}\right)+\frac{Q_{i, 1}}{\Delta x}\right\}
\end{gathered}
$$

where $\eta_{i, 2}$ and $\eta_{i, 1}$ represent surface elevations at new and old time levels, respectively; $\Delta t=$ time step; $\Delta x=$ segment length; $B_{i, k}=$ width of the $k$ th layer; $S T B_{i}=$ equivalent width of the side storage area; $B E J_{i, 1}=$ additional equivalent width contributed by tributary; $w_{i, k, 1}=$ vertical velocity at the bottom of the $k$ th layer at old time level; and $Q_{i, k}=$ lateral inflow to the $k$ th layer. The advective terms are

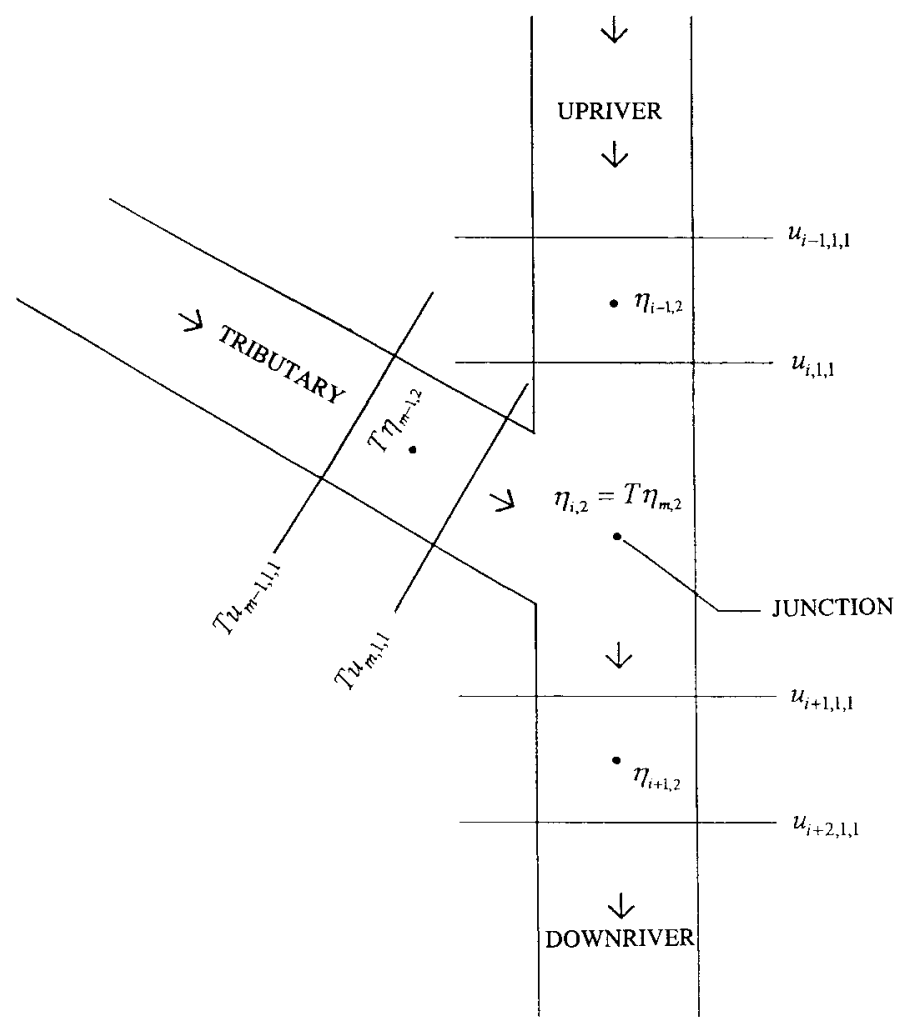

FIG. 1. Schematic Diagram Showing Horizontal Computation Grids at Mainstem Tributary Junction 


$$
\begin{gathered}
T M P_{i}=\frac{B_{i-1,1}+B_{i, 1}}{2} \frac{\left(h_{1}+\eta_{i-1,1}\right)+\left(h_{1}+\eta_{i, 1}\right)}{2} u_{i, 1,1} \\
T M P B_{m}=\frac{T B_{m-1,1}+T B_{m, 1}}{2} \frac{\left(T h_{1}+T \eta_{m-1,1}\right)+\left(T h_{1}+T \eta_{m, 1}\right)}{2} T u_{m, 1,1}
\end{gathered}
$$

where $h_{1}=$ thickness of the first layer below mean sea level; $u_{i, k, 1}=$ longitudinal velocity at old time step; and $T B, T \eta, T h$, and $T u=$ width, surface elevation, layer thickness, and longitudinal velocity at tributaries, respectively. The subscripts $i, m$, and 1 denotes the mainstem segment, tributary segment, and the top layers, respectively. The side storage area in each segment will act as a source for the main channel on the falling tide and as a sink on the rising tide. The junction segment is considered as the end segment of the tributary such that the longitudinal velocity for the tributary $T u_{m+1, k, 2}=0$, and

$$
T \eta_{m, 1}=\eta_{i, 1} ; \quad T \eta_{m, 2}=\eta_{i, 2}
$$

\section{Treatment of Conservation of Water Mass at Junction}

At the junction of mainstem and tributary (Fig. 2), the finitedifference form of the laterally integrated continuity equation $[(1)]$ is written as

$$
\begin{aligned}
& w_{i, k-1,2}=\frac{1}{\frac{B_{i, k-1}+B_{i, k}}{2}+B E J_{i, k-1}} \cdot\left\{\left(\frac{B_{i, k}+B_{i, k+1}}{2}+B E J_{i, k}\right) w_{i, k, 2}\right. \\
& -\frac{h_{k}}{\Delta x}\left[\frac{B_{i, k}+B_{i+1, k}}{2} u_{i+1, k, 2}-\frac{B_{i-1, k}+B_{i, k}}{2} u_{i, k, 2}\right. \\
& \left.\left.-\frac{T B_{m-1, k}+T B_{m, k}}{2} T u_{m, k, 2}\right]+\frac{Q_{i, k}}{\Delta x}\right\}
\end{aligned}
$$

for $k=2$ to $N$ (bottom layer) and $w_{i, N, 2}=0$.

At the junction segment, the vertical velocity in the tributary is equal to that in mainstem, that is

$$
T w_{i, k, 1}=w_{m, k, 1} ; \quad T w_{i, k, 2}=w_{m, k, 2}
$$

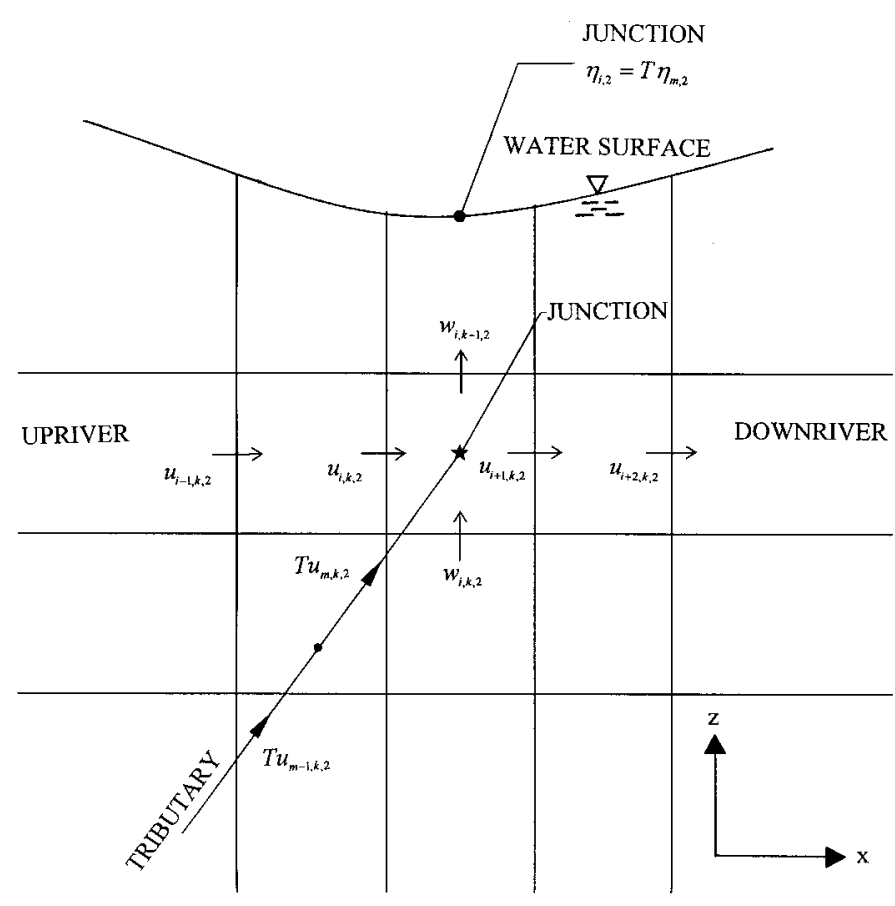

FIG. 2. Schematic Diagram Showing Vertical Computation Grids at Mainstem Tributary Junction

\section{Treatment of Conservation of Longitudinal Momentum at Junction}

Because of the spatially staggered grid used in the model, no representative longitudinal velocity is situated at the junction point of the branching model (Fig. 1). The momentum balance at the sections surrounding the junction point is handled by neglecting the horizontal advective term $(\partial / \partial x)\left(u_{k} B_{k} u_{k} h_{k}\right)$ and the turbulent diffusion term $(\partial / \partial x)\left[\left(A_{x}\right)_{k} B_{k} h_{k}(\partial u / \partial x)_{k}\right]$. The magnitudes of these two terms in the momentum equation are assumed to be locally negligible in comparison to other terms. Computational tests suggest that this is a realistic assumption.

\section{Treatment of Conservation of Salt at Junction}

At the junction segment, the additional fluxes of salt from or to the tributary are fully taken into account. The QUICKEST scheme is used to express the finite-difference form of advective term. It is based on a conservative control volume formation and estimates cell wall concentrations with a quadratic interpolation using concentrations in two adjacent cells and that at the next upstream cell. The same method is used to treat the salt concentration at the junction of mainstem and tributary, and

$$
\begin{aligned}
& T s_{m, k, 1}=s_{i, k, 1} ; \quad T s_{m+1, k, 1}=s_{i+1, k, 1} \\
& T s_{m, k, 2}=s_{i, k, 2} ; \quad T s_{m+1, k, 2}=s_{i+1, k, 2}
\end{aligned}
$$

A full description of the branching model including detailed explanation of the method of the solution, boundary conditions, turbulence closure model can be found in Hsu et al. (1996).

\section{PROCEDURE FOR MODEL CALIBRATION}

The model described in the previous section has been applied to the tidal Tanshui River system (Fig. 3), which is the largest tidal river in Taiwan. The river system has a total drainage area of $2,726 \mathrm{~km}^{2}$, a total channel length of $327.6 \mathrm{~km}$, and consists of three major tributaries: (1) The Tahan Stream; (2) Hsintien Stream; and (3) Keelung River. The downstream reaches of all three tributaries are influenced by tide. The calibration of the model to the tidal Tanshui River system is accomplished in three steps.

\section{Preliminary Calibration}

Friction dissipates energy as the tidal wave propagates landward from the river mouth. With river geometry and tidal range at the river mouth given, the magnitude of the friction coefficient determines the tidal range variation along the river. Therefore, we recommend using the distribution of the tidal range as a function of distance from the river mouth to calibrate the friction coefficient.

To seek upstream boundary conditions not influenced by tide, the computational domain of a model should be extended to or beyond the tidal limits in the tributaries as well as the mainstem. For tidal rivers with a well-defined fall line, the tidal limits locate at fixed points. They are the ideal locations as upstream boundaries of model domain. The boundary condition there may be specified with freshwater discharge as mass input without contribution to momentum. For tidal rivers with a bottom elevation rising gradually above mean sea level, the tidal limits move up or down the rivers in response to a decrease or increase of freshwater discharges. The model limit should be at a location where the bottom elevation is higher than high tide level. The freshwater discharge should contribute both mass and momentum at this type of upstream boundary condition. The Tanshui River system is of the second type 
of boundary condition. For the modeling purpose, the Tahan Stream-Tanshui River is regarded as the mainstem of the river, while the Hsintien Stream and the Keelung River are treated as the first and the second branch, respectively (Fig. 3). The model is supplied with data describing the geometry of the
Tanshui River system. The geometry in the vertical 2D model is represented by the width at each layer at the center of each grid cell. A field survey in 1994 made by the Taiwan Bureau of Water Conservancy collected the cross-sectional profiles about every $0.5 \mathrm{~km}$ along the tidal portion of the river. These

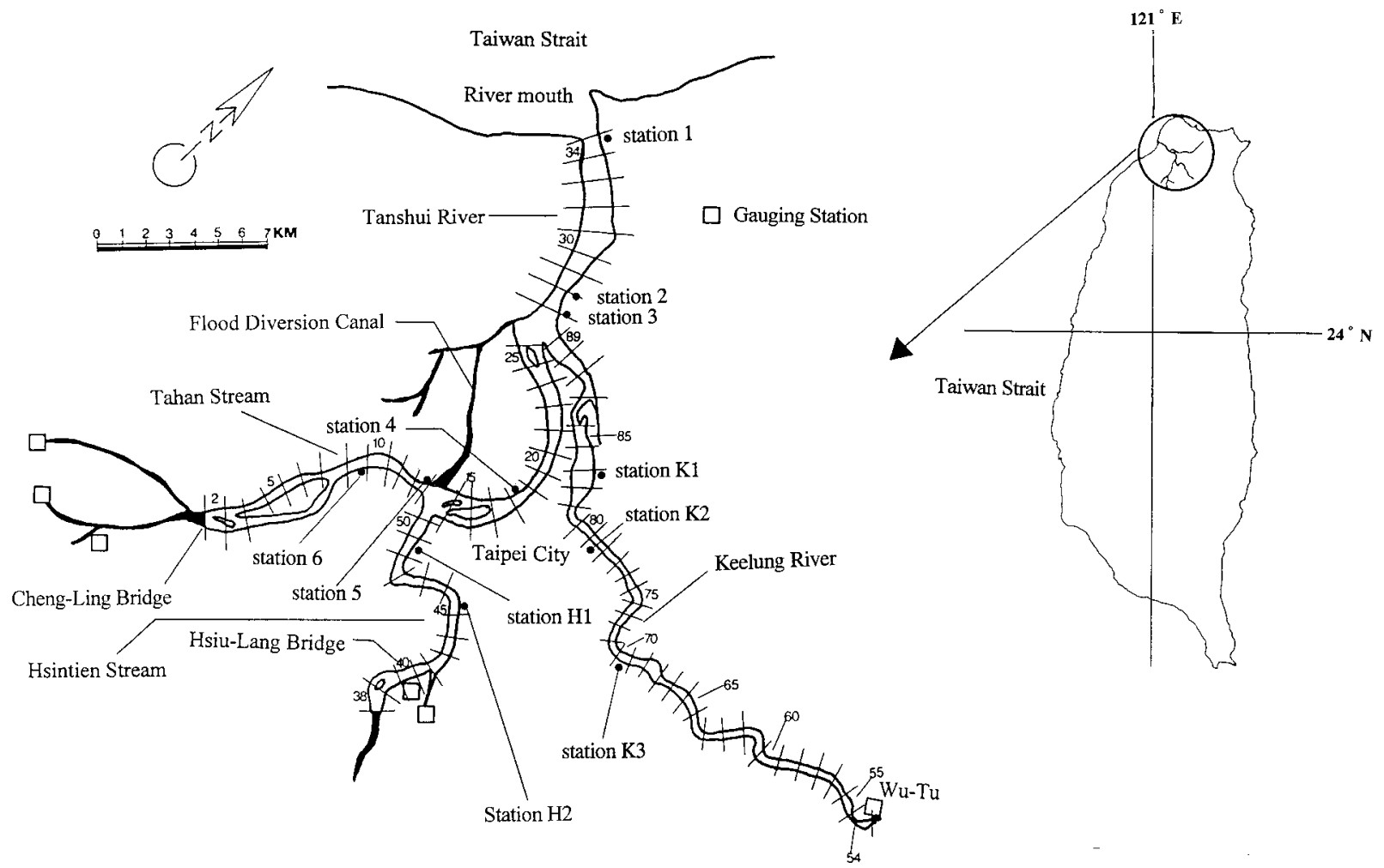

FIG. 3. Tidal Tanshui River System in Taiwan: Lines Are Model Transects at 1.0-km Interval; Numbers Are Model Segment Numbers

Tanshui River-Tahan Stream

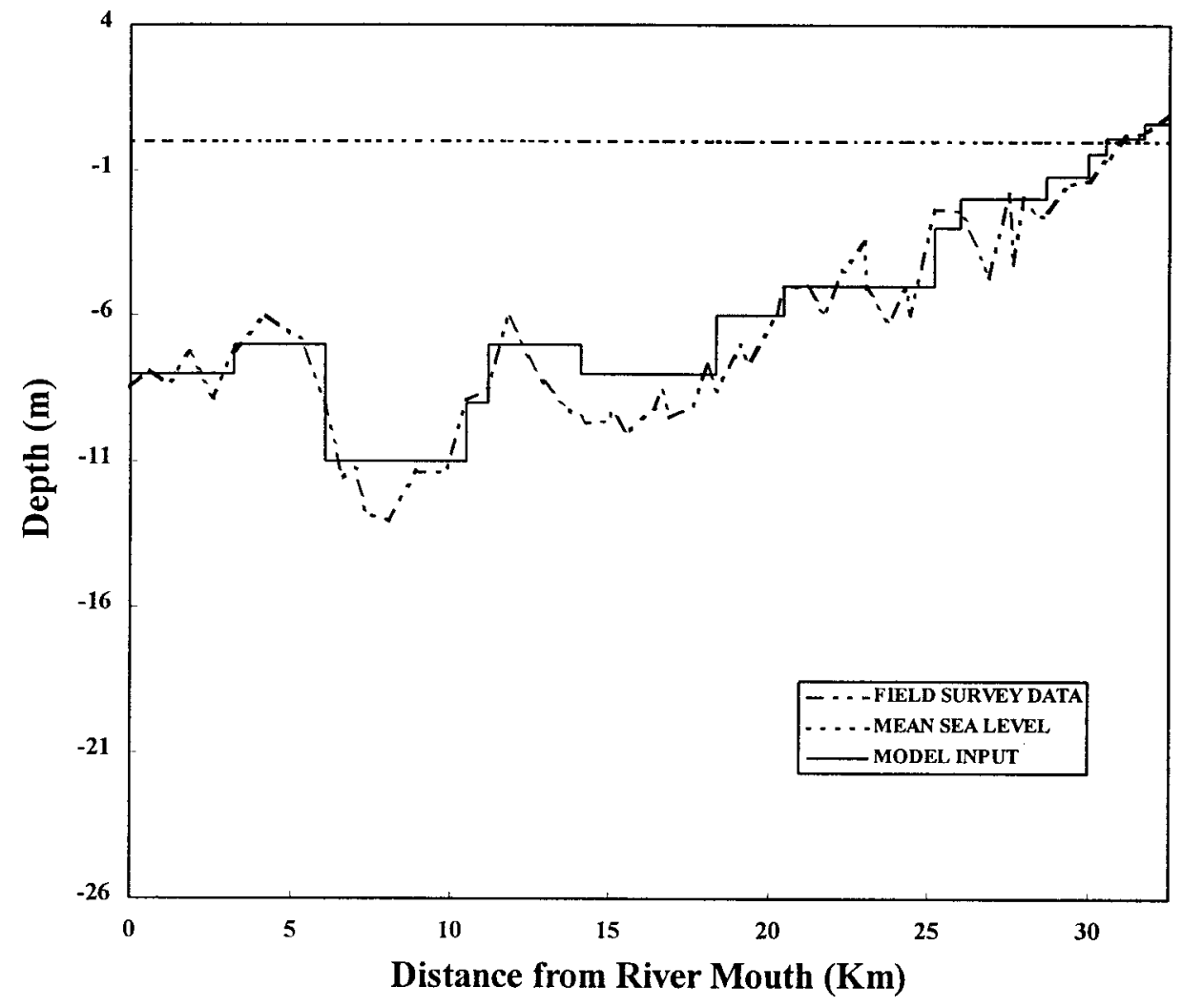

FIG. 4. Longitudinal Bottom Profile of Tanshui River-Tahan Stream 


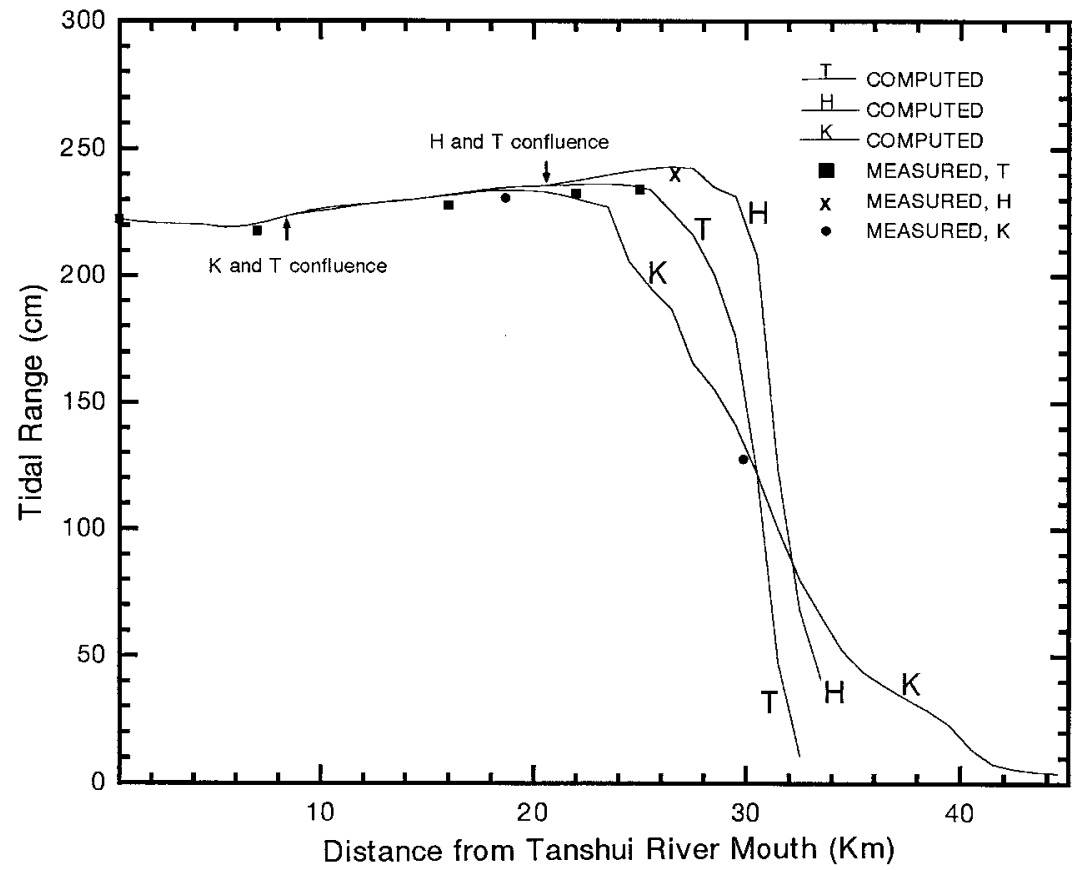

FIG. 5. Preliminary Calibration: Comparison of Tidal Ranges (T: Tanshui River-Tahan Stream, H: Hsintien Stream, K: Keelung River)

profiles were used to schematize the river. The river system is divided into 33,14 , and 37 segments $(\Delta x=1.0 \mathrm{~km})$. Because surface elevation at low tide is $\sim 1.5$-m below mean sea level at spring tide, the thickness of the top layer is $2.0 \mathrm{~m}$ to maintain surface elevation above the bottom of the layer at all times. The thickness of other layers is $1.0 \mathrm{~m}$. The measured cross-sectional profiles in each segment were averaged and schematized. First, the bottom elevation was determined at an integral number of meters below mean sea level. Then the width at each layer was determined while maintaining the cross-sectional area roughly the same as the measured profiles. Fig. 4 shows, as an example, the bottom profiles of the schematized cross section and the deepest point of measured section along the Tanshui River-Tahan stream. The layer number of a segment was adjusted if it turned out to be deeper than the two adjacent segments to avoid a dead hole. The time step $\Delta t$ is limited by Courant-Fredrick-Levy stability condition $\Delta t$ $\leq \Delta x / \sqrt{g h}$. A time step increment $(\Delta t)$ of $108 \mathrm{~s}$, which guaranteed stability, was used for all model runs.

A single constituent tide was used as a forcing function at the river mouth for preliminary model calibration. The use of a single constituent expedites the extraction of tidal ranges from model outputs for comparison with prototype data. Because an $M_{2}$ tide is dominant in the Tanshui River system, it was used for model calibration. The downstream boundary condition is an $M_{2}$ tide with amplitude being half of the mean tidal range, $111 \mathrm{~cm}$, calculated from 365-day data measured at the river mouth in 1994 and the observed mean surface elevation, $10.7 \mathrm{~cm}$. The upstream boundary conditions at the three tributaries are the mean discharges of 1994. The model was run for 30 tidal cycles to reach dynamic equilibrium; that is, the computed velocities and surface elevations at all segments remain unchanged from one tidal cycle to the next. The differences between the maximum and minimum surface elevations in the last tidal cycle was output as the tidal range for each model segment. The friction coefficient was adjusted until the model outputs agreed satisfactorily with the mean tidal ranges calculated from the 1994 data. The calibration process started with a uniform Manning's friction coefficient. The value of the friction coefficient for a particular reach of the river was then adjusted up or down as the comparison of model results and field data dictated. This is a trial and error process without a systematic approach. However, there is a guiding principle that an increase in the friction coefficient will lower the tidal ranges both in that reach of the river and that upstream of it. Another principle used in the fine-tune calibration is that an increase in the friction coefficient will increase the phase lags for both high and low tides.

Fig. 5 shows the comparisons of the final results. It shows the elevation of the tidal range along the axes of the river and its tributaries. The tidal range is affected by the river geometry as well as bottom friction. The friction dissipates tidal energy and reduces the tidal range as the tide propagates upriver. The river geometry may cause the tidal range to increase or decrease as the river cross section contracts or expands. Green's law (Ippen 1966) states that the tidal range is inversely proportional to the square root of the river width, and one-fourth power of depth under the frictionless condition. All three branches of the Tanshui River system have a general trend of decreasing width and depth landward beyond the confluence of the Tanshui and Keelung rivers, resulting in increasing tidal range in upriver direction. The slight landward decrease of the tidal range near the river mouth may be the result of high frictional energy loss in that reach of the river $(n=0.032)$. At the uppermost reaches of all three branches the tidal range decreases sharply as the result of the rapid rise in the river bottom. Finally the tidal range reaches its limit when the river bottom rises above high tide level. The Keelung River has a more gentle decrease of the tidal range because of its more gentle bottom slope (see the bottom profiles in Fig. 8). Fig. 5 also indicates that the tidal range predicted by the model is slightly higher than most of the field data. This is the result of fine-tune calibration described in the following section. After determination of the friction coefficient by fitting the mean tidal range, the friction coefficient was further adjusted to achieve fine-tune calibration of the multiple constituent tide, resulting in a worse comparison of mean tidal ranges than originally achieved. The average absolute values of differences (mean absolute errors) between computed and measured tidal ranges is $3.4 \mathrm{~cm}$, while the root-mean-square error is $3.8 \mathrm{~cm}$, both of which are $<2 \%$ of mean tidal range.

It is worthwhile to note that half of mean tidal range, not the amplitude of an $M_{2}$ tide from the harmonic analysis, was used as amplitude of an $M_{2}$ tide to force the model for model 
calibration. In the case of the Tanshui River system, the other tidal constituents account for a significant amount of tidal energy. If an $M_{2}$ tide with amplitude obtained from the harmonic analysis was used for model calibration, it would underestimate the tidal energy and result in overestimation of the friction coefficient. This would cause difficulty when a multiple constituent tide was used to fine-tune the model.

TABLE 1. Amplitudes and Phases of Tidal Constituents at River Mouth

\begin{tabular}{c|c|c|c|c}
\hline \hline $\begin{array}{c}\text { Number } \\
(1)\end{array}$ & $\begin{array}{c}\text { Tidal } \\
\text { constituent } \\
(2)\end{array}$ & $\begin{array}{c}\text { Period } \\
(\mathrm{hr}) \\
(3)\end{array}$ & $\begin{array}{c}\text { Amplitude } \\
(\mathrm{cm}) \\
(4)\end{array}$ & $\begin{array}{c}\text { Phase } \\
\text { (degree) } \\
(5)\end{array}$ \\
\hline 1 & $M_{2}$ & 12.42 & 105.1 & 35.7 \\
2 & $S_{2}$ & 12.00 & 27.7 & -7.3 \\
3 & $N_{2}$ & 12.66 & 21.0 & -45.1 \\
4 & $K_{1}$ & 23.93 & 19.9 & -133.8 \\
5 & $S_{a}$ & 8765 & 17.1 & -143.3 \\
6 & $O_{1}$ & 25.82 & 16.2 & -47.8 \\
7 & $K_{2}$ & 11.97 & 7.2 & 32.4 \\
8 & $P_{1}$ & 24.07 & 7.1 & -110.5 \\
9 & $M_{4}$ & 6.21 & 2.8 & 47.8 \\
10 & $L_{2}$ & 12.19 & 6.4 & -55.6 \\
11 & $N u_{2}$ & 12.63 & 5.0 & 161.8 \\
12 & $M u_{2}$ & 12.87 & 4.4 & -101.5 \\
13 & $Q_{1}$ & 26.87 & 3.2 & -121.7 \\
14 & $S S a$ & 4383 & 3.2 & 157.1 \\
15 & $2 N$ & 12.91 & 3.9 & -148.5 \\
16 & $M_{2} S_{2}$ & 6.10 & 1.9 & 4.2 \\
17 & $M s f$ & 354.4 & 1.9 & 150.8 \\
18 & $M_{2} N_{2}$ & 6.27 & 1.1 & -27.5 \\
19 & $M m$ & 661.3 & 1.7 & 159.3 \\
20 & $M_{6}$ & 4.14 & 0.5 & 80.5 \\
\hline \hline
\end{tabular}

TABLE 2. Comparison of Harmonic Analyses with Various Numbers of Constituents

\begin{tabular}{c|c|c|c|c|c|c}
\hline \hline & \multicolumn{6}{|c}{ Number of Tidal Constituents } \\
\cline { 2 - 7 } $\begin{array}{c}\text { Comparison } \\
(1)\end{array}$ & $\begin{array}{c}20 \\
(2)\end{array}$ & $\begin{array}{c}15 \\
(3)\end{array}$ & $\begin{array}{c}11 \\
(4)\end{array}$ & $\begin{array}{c}9 \\
(5)\end{array}$ & $\begin{array}{c}5 \\
(6)\end{array}$ & $\begin{array}{c}2 \\
(7)\end{array}$ \\
\hline $\begin{array}{c}\text { Residual surface } \\
\text { elevation (cm) }\end{array}$ & 11.49 & 11.73 & 12.84 & 14.06 & 19.59 & 33.83 \\
Energy ratio (\%) & 98.07 & 98.00 & 97.59 & 97.11 & 94.40 & 83.29 \\
\hline \hline
\end{tabular}

\section{Fine-Tune Calibration of Friction Coefficient}

Even though a single constituent $M_{2}$ tide can properly simulate the tidal energy propagation up the estuary, the timevarying surface variation it represents is far from the prototype condition. A model calibrated with respect to mean tidal range does not guarantee proper simulation with respect to other features of tidal propagation, in particular the tidal phase. Tidal phase may be represented by the phase relationship among the significant harmonic constituents, as well as the overall times of high and low tides at various locations in the estuary. The time series field data is affected by the temporally varying freshwater discharges and the random meteorological forcing, as well as the amplitudes and phase relationship of the various tidal constituents. To focus on a particular aspect of the dynamic forcing and simplify the calibration process, it is proposed that the model be fine-tuned with astronomical tide only. This approach also eliminates the uncertainty caused by measuring errors in field data. The satisfactory comparison with field data will serve as verification that the model properly simulates all of the forcings combined.

The time series data of surface elevation at eight stations, collected by the Taiwan Bureau of Water Conservancy, were examined and analyzed. First, harmonic analysis was performed on the observed data at the river mouth with 20 constituents. There was little difference in the resulting constituent's amplitudes and phase relations whether analyzed with 1-, 2-, or 3-year data. Therefore, 1-year data were used for most of the subsequent analyses. To choose a suitable number of tidal constituents, 20,15,11, nine, five, and two constituents were used to make harmonic analysis. In each analysis, the tidal constituents were selected according to the results of 20 constituent analyses (Table 1). The constituents with the largest amplitudes were selected, plus an $M_{4}$ tide, expecting its amplitude to increase in the upriver direction due to the nonlinear friction term in the momentum equation. Table 2 compares the residual surface elevation and energy ratio of the tidal wave for a different number of tidal constituents. Residual surface elevation is the root-mean square (RMS) of the difference between the synthetic tidal surface elevation and observed surface elevation. That is

$$
\operatorname{RMS}=\left\{\frac{1}{N} \sum_{i=1}^{N}\left[\eta\left(t_{i}\right)-\eta_{p}\left(t_{i}\right)\right]^{2}\right\}^{1 / 2}
$$

TABLE 3. Differences in Amplitudes and Phases of Harmonic Constituents between Computed and Observed Tide

\begin{tabular}{|c|c|c|c|c|c|c|c|c|}
\hline \multirow[b]{2}{*}{$\begin{array}{c}\text { Constituent } \\
\text { (1) }\end{array}$} & \multicolumn{6}{|c|}{ Station } & \multirow{2}{*}{$\begin{array}{c}\text { Mean absolute } \\
\text { error } \\
\text { (degree) } \\
(8)\end{array}$} & \multirow{2}{*}{$\begin{array}{c}\text { Root-mean- } \\
\text { square error } \\
\text { (degree) } \\
\text { (9) }\end{array}$} \\
\hline & $\begin{array}{c}2 \\
\text { (degree) } \\
(2)\end{array}$ & $\begin{array}{c}4 \\
\text { (degree) } \\
(3)\end{array}$ & $\begin{array}{c}5 \\
\text { (degree) } \\
(4)\end{array}$ & $\begin{array}{c}6 \\
\text { (degree) } \\
(5)\end{array}$ & $\begin{array}{c}\mathrm{H} 2 \\
\text { (degree) } \\
(6)\end{array}$ & $\begin{array}{c}\mathrm{K} 2 \\
\text { (degree) } \\
(7)\end{array}$ & & \\
\hline \multicolumn{9}{|c|}{ (a) Amplitude } \\
\hline $\begin{array}{l}M_{2} \\
S_{2} \\
N_{2} \\
K_{1} \\
S_{a} \\
O_{1} \\
K_{2} \\
P_{1} \\
M_{4} \\
\end{array}$ & $\begin{array}{r}-0.83 \\
-2.60 \\
-0.82 \\
-0.46 \\
0.81 \\
-0.75 \\
-0.57 \\
1.33 \\
1.30 \\
\end{array}$ & $\begin{array}{r}-0.11 \\
-0.58 \\
2.51 \\
-0.10 \\
-4.77 \\
-1.09 \\
-3.66 \\
1.34 \\
2.84 \\
\end{array}$ & $\begin{array}{r}-2.12 \\
-0.04 \\
0.24 \\
0.51 \\
0.02 \\
1.24 \\
-0.47 \\
0.40 \\
5.57 \\
\end{array}$ & $\begin{array}{r}-4.06 \\
-1.83 \\
-1.05 \\
0.78 \\
-2.31 \\
1.44 \\
-0.12 \\
0.35 \\
5.99 \\
\end{array}$ & $\begin{array}{r}-5.14 \\
-1.63 \\
-0.19 \\
0.64 \\
-17.94 \\
1.28 \\
-0.20 \\
0.34 \\
7.21 \\
\end{array}$ & $\begin{array}{r}-3.52 \\
-3.37 \\
0.79 \\
-1.60 \\
-9.66 \\
-1.49 \\
-3.56 \\
0.83 \\
2.76 \\
\end{array}$ & $\begin{array}{l}2.63 \\
1.68 \\
0.93 \\
0.68 \\
5.92 \\
1.22 \\
1.43 \\
0.77 \\
4.28 \\
\end{array}$ & $\begin{array}{l}3.17 \\
2.02 \\
1.21 \\
0.82 \\
8.60 \\
1.24 \\
2.11 \\
0.88 \\
4.76 \\
\end{array}$ \\
\hline \multicolumn{9}{|c|}{ (b) Phase } \\
\hline $\begin{array}{l}M_{2} \\
S_{2} \\
N_{2} \\
K_{1} \\
S_{a} \\
O_{1} \\
K_{2} \\
P_{1} \\
M_{4} \\
\end{array}$ & $\begin{array}{r}0.07 \\
5.89 \\
0.70 \\
4.87 \\
-12.25 \\
5.36 \\
-1.19 \\
8.45 \\
10.20 \\
\end{array}$ & $\begin{array}{r}5.23 \\
13.38 \\
10.83 \\
12.61 \\
3.56 \\
16.55 \\
-5.55 \\
21.61 \\
-2.07 \\
\end{array}$ & $\begin{array}{r}-6.68 \\
-1.86 \\
-5.92 \\
6.24 \\
-2.35 \\
2.78 \\
-6.08 \\
-6.94 \\
-1.39 \\
\end{array}$ & $\begin{array}{r}6.18 \\
16.54 \\
11.94 \\
16.04 \\
-14.70 \\
13.38 \\
0.18 \\
1.97 \\
23.29 \\
\end{array}$ & $\begin{array}{r}4.42 \\
11.18 \\
5.63 \\
15.91 \\
-17.06 \\
12.47 \\
-9.43 \\
-1.19 \\
19.77 \\
\end{array}$ & $\begin{array}{r}11.66 \\
16.85 \\
17.80 \\
16.47 \\
-1.53 \\
18.29 \\
8.21 \\
-1.04 \\
13.15 \\
\end{array}$ & $\begin{array}{r}5.71 \\
10.95 \\
8.80 \\
12.02 \\
8.58 \\
11.47 \\
5.11 \\
6.87 \\
11.65 \\
\end{array}$ & $\begin{array}{r}6.65 \\
12.24 \\
10.36 \\
12.93 \\
10.63 \\
12.78 \\
6.13 \\
9.94 \\
14.28 \\
\end{array}$ \\
\hline
\end{tabular}


where $\eta(t)=$ observed surface elevation; $\eta_{p}(t)=$ synthetic tidal surface elevation; and

$$
\eta_{p}(t)=\bar{\eta}+\sum_{k-1}^{m} a_{k} \cos \left(\omega_{k} t-\theta_{k}\right)
$$

$\bar{\eta}=$ mean surface elevation; $\omega_{k}=$ angular velocity $\left(=2 \pi / T_{k}\right) ;$ $T_{k}=$ period of tidal constituent; $a_{k}$ and $\theta_{k}=$ amplitude and phase, respectively; and $m=$ number of constituents. The energy ratio (ER) represents the ratio of the energy of water surface fluctuation of synthetic tide to that of observed tide. That is

$$
\mathrm{ER}=\frac{\sum\left[\eta_{p}\left(t_{i}\right)-\bar{\eta}\right]^{2}}{\sum\left[\eta\left(t_{i}\right)-\bar{\eta}\right]^{2}} \times 100 \%
$$

Table 2 shows that as the number of tidal constituents used in harmonic analysis increases, the residual surface elevation decreases and the energy ratio of the wave approaches 1.0 (i.e., the synthetic tide becomes a better representation of observed water surface elevation). The table also shows that there is a significant improvement of synthetic tide when the constituent number increases from five to nine, while the improvement drastically reduces with more than nine constituents. More than $97 \%$ of energy of the observed water surface fluctuation is represented by a nine-constituent tide. Therefore, a nineconstituent tide was used for the following model application when a synthetic tide was employed to specify the downstream boundary condition. The nine constituents are $M_{2}(12.42 \mathrm{~h})$, $S_{2}(12 \mathrm{~h}), N_{2}(12.9 \mathrm{~h}), K_{1}(23.93 \mathrm{~h}), S_{a}(8,765.32 \mathrm{~h}), O_{1}(25.82$ h), $K_{2}(11.97 \mathrm{~h}), P_{1}(24.07 \mathrm{~h})$, and $M_{4}(6.21 \mathrm{~h})$.

The model was fine-tuned with a synthetic tide as a forcing function at the river mouth. Amplitudes and phases of nine tidal constituents were specified to generate the downstream boundary condition of surface elevation for the 1-year (705 tidal cycles) model simulation. Harmonic analysis was performed on the time series data of model outputs of surface elevation at various locations. After a slight local adjustment of the Manning coefficient, Table 3 shows the mean absolute errors and root-mean-square errors in amplitudes and phases of harmonic constituents between computed and observed tide. The differences are in a reasonable range. While the phases of harmonic constituents at various locations are mainly affected by friction, their amplitudes are damped by friction and amplified or diminished by the changing geometry along the river. Furthermore, the generation of an $M_{4}$ tide is the result of the nonlinear terms.

It is worthwhile noting that the largest errors listed in Table 3(a) are associated with the two ends of the frequency spectrum (i.e., the $S_{a}$ and $M_{4}$ tidal constituents). This may be attributed to the intrinsic characteristics of digital data analysis. At the low frequency end, the 1-year data, or model results, contain only one period of an $S_{a}$ tide, while at the high frequency end, each period of an $M_{4}$ tide contains only six- or seven-hourly data points. It is expected that the errors may be reduced by increasing both the duration and sampling frequency of prototype data and model simulation.

Kuo and Park (1995) demonstrated that proper simulation of times of high and low tides are important. If the side storage area is not properly accounted for, the model can reproduce the mean tidal range but the phase cannot be properly simulated. Fig. 6 compares the times of high tide and low tide between model results and observations. It shows that the time lag of high tide is shorter than that of low tide, because the wave propagates slower in shallower water at low tide. The difference in the model results and observations are $<10 \mathrm{~min}$
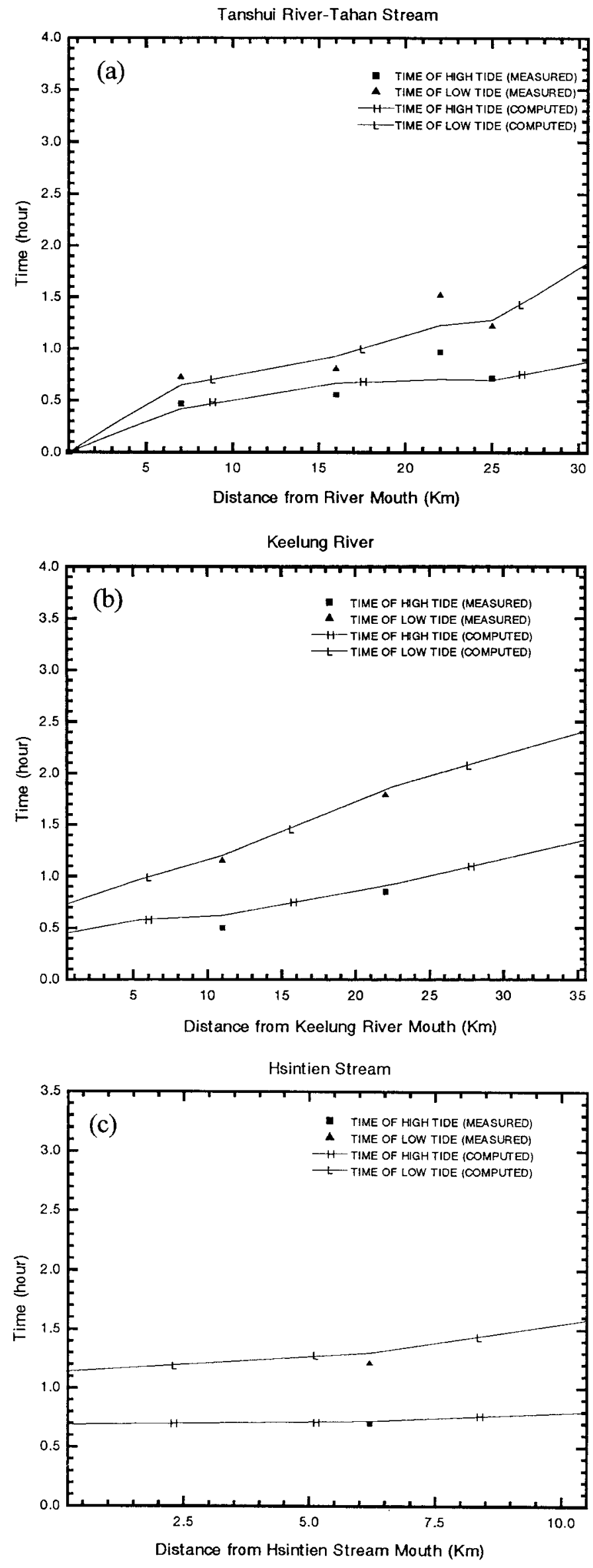

FIG. 6. Fine-Tune Calibration: Average Times of High and Low Tides Relative to Those at River Mouth: (a) Tanshui River-Tahan Stream; (b) Keelung River; (c) Hsintien Stream 


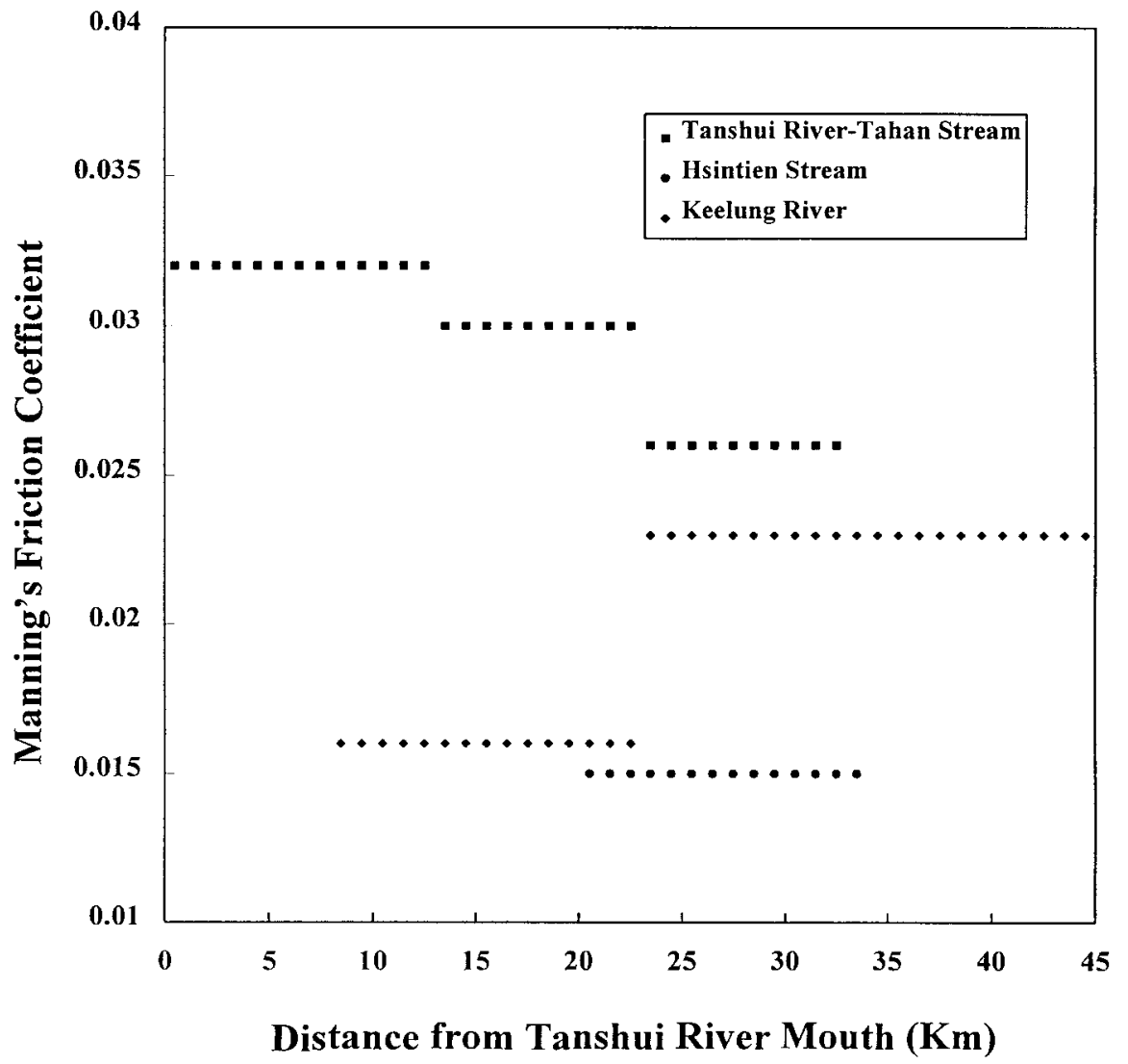

FIG. 7. Values of Manning's Friction Coefficient

except at one station where a tide gauge was located away from the main channel at the entrance to the flood diversion canal.

The values of Manning's friction coefficient used in the final calibrated model are presented in Fig. 7. The lower value of 0.015 in the Hsintien Stream may be associated with the fact that most of the bottom material is fine sand in this stream. The major portion of the lower reach of the Keelung River was straightened and lined with an artificial hard bottom and side banks under a channel regulation project in 1993, thus, resulting in a low friction coefficient. The higher friction coefficient in the Tanshui River-Tahan Stream is due to the channel irregularity as well as coarser bed material. A vertical 2D model cannot simulate a local flow field at a river bend or around an island. The energy dissipation by the transverse flows in these areas has to be accounted for in the friction term, which is formulated with Manning's formula in this model. Therefore, the friction coefficient includes the geometric effect and has a higher value when river geometry becomes more irregular.

In some model studies, time series data of velocities, or their harmonic constituent, are included in the calibration process. However, we propose that the comparison of model-calculated velocities with the field data be treated as model verification. Unlike surface elevation, current velocity varies rapidly, both in magnitude and direction, from point to point in space, reflecting the often irregular river geometry. There are intrinsic differences between the model result and prototype data. The model result represents the average value over some spatial domain of grid size or segment length while the prototype data is the value at a single point or, at best, an average over several points if the model is not 3D. To calibrate the model so that it closely reproduces the velocity measurements does not necessarily imply model accuracy. Furthermore, after the preliminary and fine-tune calibration as described earlier, the further adjustment of the friction coefficient to match the velocity data often results in degrading calibration of surface elevation for which the field data are much more reliable. It is suggested that the use of velocity information for model calibration be reserved for cases in which no sufficient data are available to discern the spatial variation of the tidal range.

\section{Calibration of Mixing Processes}

In most estuaries with a significant freshwater discharge, salinity may serve as an ideal natural tracer for calibration of mixing processes. Salinity distribution in an estuary is affected by the tidal current, freshwater discharge, density circulation, as well as turbulent mixing processes. Therefore the salinity distribution reflects the combined results of all processes, and in turn it controls density circulation and modifies mixing processes. Assuming the barotropic flows (i.e., tidal and freshwater flows) have been calibrated, and will be verified, as described in the previous and next sections, we recommend proceeding to calibrate the coefficients in the turbulence model by matching the observed and computed salinity distributions. Because the interaction among turbulent mixing, salinity distribution, and density current is a feedback system, this step of the model calibration is not straightforward.

In the present model, the mixing processes are modeled with turbulent diffusion terms. The mixing length concept is used to calculate eddy viscosity $A_{z}$ and diffusion coefficient $K_{z}$ in the vertical direction. The following formulations similar to those proposed by Pritchard (1960) are used:

$$
\begin{aligned}
A_{z} & =\alpha Z^{2}\left(1-\frac{Z}{h}\right)^{2}\left|\frac{\partial u}{\partial z}\right|(1+\beta \mathrm{R})^{(-1) / 2} \\
& +\alpha_{w} \frac{H_{w}^{2}}{T} \exp \left(-\frac{2 \pi}{L} Z\right)
\end{aligned}
$$




$$
\begin{aligned}
K_{z} & =\alpha Z^{2}\left(1-\frac{Z}{h}\right)^{2}\left|\frac{\partial u}{\partial z}\right|(1+\beta \mathrm{R})^{(-3) / 2} \\
& +\alpha_{w} \frac{H_{w}^{2}}{T} \exp \left(-\frac{2 \pi}{L} Z\right)
\end{aligned}
$$

where $Z=$ depth below water surface; $h=$ total depth $(=H+$ $\eta) ; \mathrm{R}=$ local Richardson number; $H_{w}, T$, and $L=$ height, period, and length of wind-induced waves, respectively; and the constants $\alpha, \beta$, and $\alpha_{w}$ need to be determined through a calibration process. We recommend that the model be calibrated first without wind mixing, using data measured at a time when no significant wind exists. Then $\alpha_{w}$ can be calibrated, if salinity data during period of strong wind are available.

The constants $\left(\alpha, \beta\right.$, and $\left.\alpha_{w}\right)$ in the expressions for the turbulent diffusion coefficients were calibrated with a simulation of salinity distributions from March 15 to June 24, 1994. Three time-varying boundary conditions - freshwater inflows through the upstream boundaries of the three branches, and the tide and salinity at the river mouth-were specified for the model run. The upstream boundary conditions were specified with daily freshwater discharges at Cheng-Ling bridge (Tahan Stream), Hsui-Lang Bridge (Hsintien Stream), and Wu$\mathrm{Tu}$ station (Keelung River). Hourly tidal elevation measured at the river mouth was used for the downstream boundary condition. The maximum salinity measured at the mouth on each survey data were linearly interpolated in time and used for the boundary condition, which specified the high tide salinity at each tidal cycle.
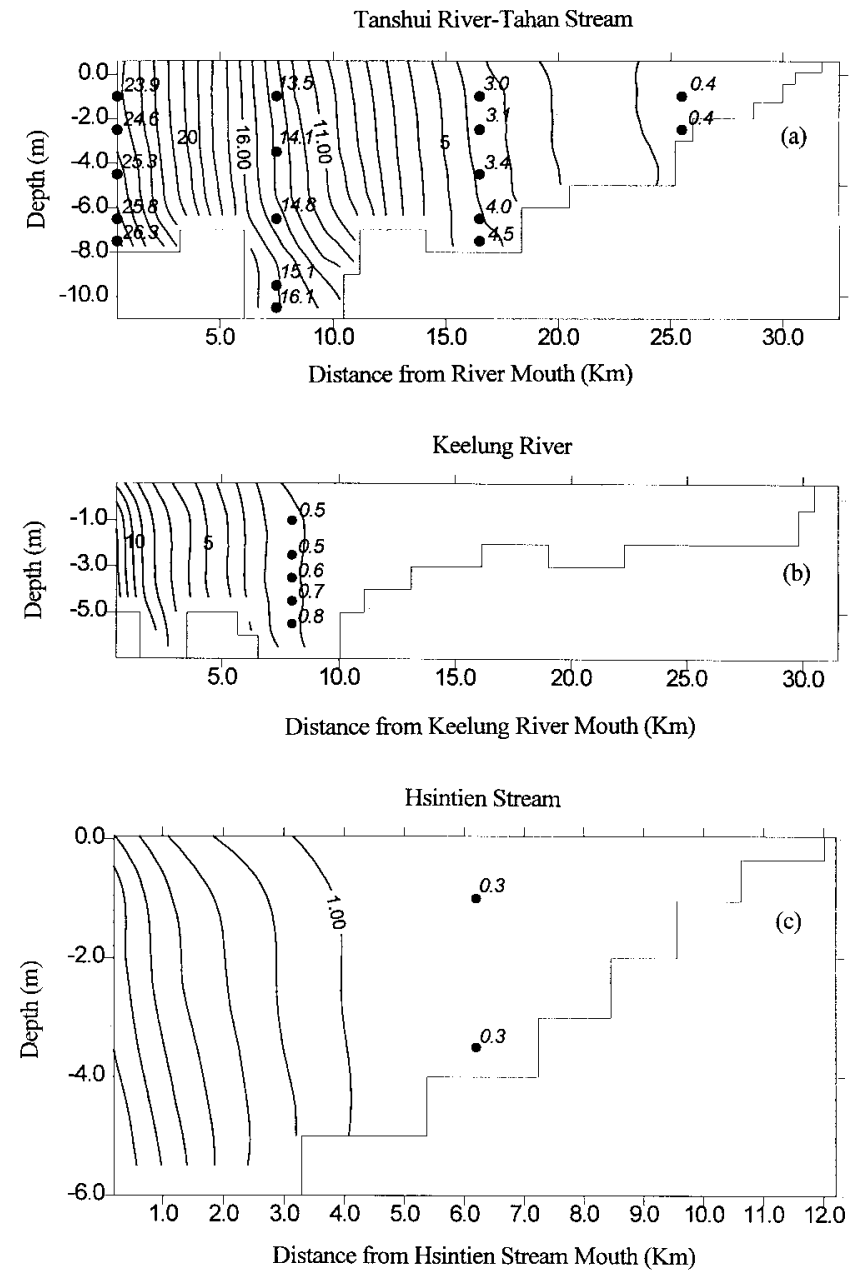

FIG. 8. Calibration of Mixing Processes: Comparison of Computed $(\longrightarrow)$ and Measured ( $\bullet$ ) Tidal Average Salinity: (a) Tanshui River-Tahan Stream, June 24, 1994; (b) Keelung River, June 24, 1994; (c) Hsintien Stream, April 12, 1994
Two sets of salinity data, measured on April 12 and June 24, 1994, are available for comparison with model results. To allow for uncertainty in the salinity initial condition, the model simulation started on March 15 with a uniform salinity of 30 ppt. Test model runs showed that the predicted salinity distribution became independent of the initial condition by April 12. Since there are more data in the mainstem on June 24 , the constants in the turbulent diffusion coefficients were adjusted primarily by the comparison of the June 24 survey data and the model results. The calibrated constants for vertical mixing are $\alpha=0.0115$ and $\beta=0.75$. No formulation of longitudinal dispersion is included in this model. They are specified as a constant for the mainstem and each of the tributaries. The calibrated values are $A_{x}=K_{x}=28 \times 10^{5} \mathrm{~cm}^{2} / \mathrm{s}$ for the Tahan Stream-Tanshui River, $A_{x}=K_{x}=3.5 \times 10^{5} \mathrm{~cm}^{2} / \mathrm{s}$ for the Hsintien Stream, and $A_{x}=K_{x}=5 \times 10^{4} \mathrm{~cm}^{2} / \mathrm{s}$ for the Keelung River. The resulting tidal average salinity distributions are presented as plots of isohalines in vertical planes containing the river axes in Fig. 8. For the Hsintien Stream, the April 12 data were used for model calibration [Fig. 8(c)]. These data indicate that, while the freshwater discharges on April 12 were much lower, the field station $\mathrm{H} 2$ was still beyond the limit of salt intrusion. The agreement in the location of the isohalines constructed from the model results and the values of field measurements reflects that the model accurately simulates transport processes.

The model predictions of the tidal average salinity on April 12 are presented in Fig. 9. The initial model run without including wind mixing [Fig. 9(b)] showed stronger stratification than that indicated by field data in the Tahan Stream. The discrepancy was attributed to the shallow depth there and wind mixing. Wind data from the Taiwan Central Weather Bureau were examined. Strong winds with peak gust speeds of 8.9 and $8 \mathrm{~m} / \mathrm{s}$ blew from the north on April 9 and 12, respectively. The effect of wind mixing was included in the subsequent simulation through the second terms in (15) and (16). The coefficient for wind mixing $\left(\alpha_{w}\right)$ was calibrated to be $5 \times 10^{-2}$. Fig. 9(a) shows the model result with wind mixing. As expected, the inclusion of wind mixing results in a less stratified water column, particularly in the shallower part of the Tahan Stream. The significance of wind mixing in a shallower part
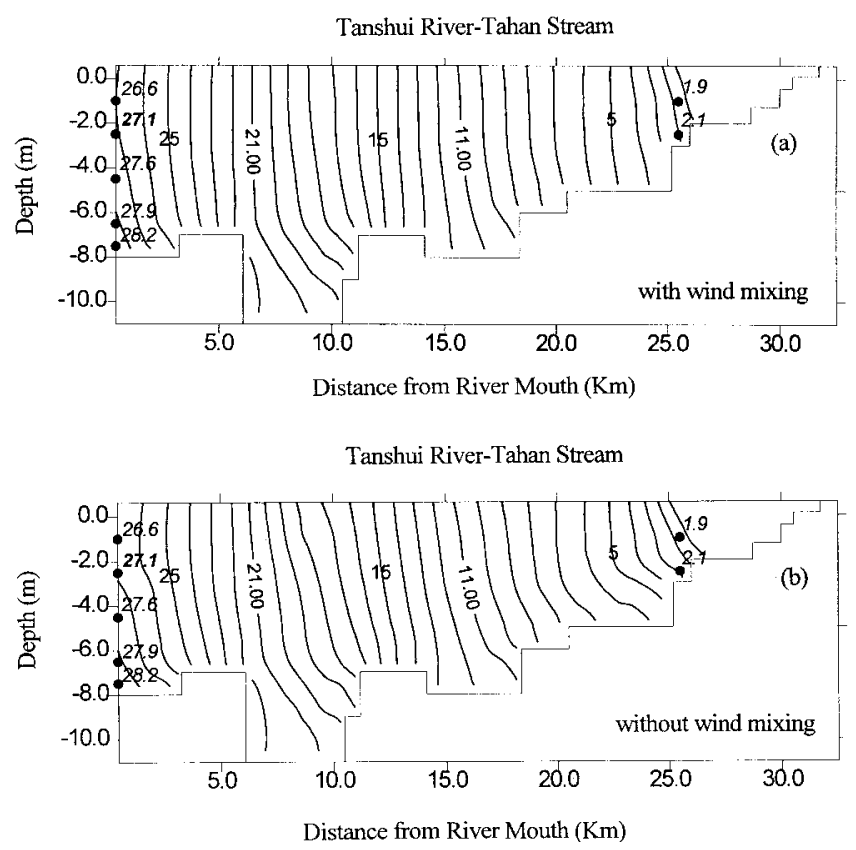

FIG. 9. Calibration of Mixing Processes: Comparison of Computed $(-)$ and Measured $(\bullet)$ Tidal Average Salinity on April 12, 1994; (a) with Wind Mixing; (b) without Wind Mixing 
TABLE 4. Mean Absolute Errors and Root-Mean-Square Errors of Differences between Computed and Measured Time Series Salinity Data

\begin{tabular}{|c|c|c|c|c|c|c|c|c|c|c|}
\hline \multirow[b]{3}{*}{$\begin{array}{l}\text { Layer } \\
\text { (1) }\end{array}$} & \multicolumn{10}{|c|}{ STATION } \\
\hline & \multicolumn{2}{|r|}{1} & \multicolumn{2}{|c|}{3} & \multicolumn{2}{|r|}{4} & \multicolumn{2}{|c|}{6} & \multicolumn{2}{|c|}{$\mathrm{K} 1$} \\
\hline & $\begin{array}{c}\text { Mean abso- } \\
\text { lute error } \\
\text { (ppt) } \\
(2)\end{array}$ & $\begin{array}{c}\text { Root-mean- } \\
\text { square error } \\
\text { (ppt) } \\
(3)\end{array}$ & $\begin{array}{c}\text { Mean abso- } \\
\text { lute error } \\
(\mathrm{ppt}) \\
(4)\end{array}$ & $\begin{array}{c}\text { Root-mean- } \\
\text { square error } \\
\text { (ppt) } \\
(5)\end{array}$ & $\begin{array}{l}\text { Mean abso- } \\
\text { lute error } \\
\text { (ppt) } \\
(6)\end{array}$ & \begin{tabular}{|} 
Root-mean- \\
square error \\
(ppt) \\
$(7)$
\end{tabular} & $\begin{array}{c}\text { Mean abso- } \\
\text { lute error } \\
\text { (ppt) } \\
(8)\end{array}$ & $\begin{array}{l}\text { Root-mean- } \\
\text { square error } \\
\text { (ppt) } \\
(9)\end{array}$ & $\begin{array}{c}\text { Mean abso- } \\
\text { lute error } \\
(\mathrm{ppt}) \\
(10)\end{array}$ & $\begin{array}{c}\text { Root-mean- } \\
\text { square error } \\
\text { (ppt) } \\
(11)\end{array}$ \\
\hline \multicolumn{11}{|c|}{ (a) April 12, 1994} \\
\hline $\begin{array}{l}\text { Surface } \\
\text { Bottom }\end{array}$ & $\begin{array}{l}0.62 \\
0.82\end{array}$ & $\begin{array}{l}0.71 \\
0.94 \\
\end{array}$ & - & - & - & - & $\begin{array}{l}0.40 \\
0.27 \\
\end{array}$ & $\begin{array}{l}0.61 \\
0.34 \\
\end{array}$ & $\begin{array}{l}0.81 \\
0.88\end{array}$ & $\begin{array}{l}1.21 \\
1.37 \\
\end{array}$ \\
\hline \multicolumn{11}{|c|}{ (b) June 24, 1994} \\
\hline $\begin{array}{l}\text { Surface } \\
\text { Bottom } \\
\text { Middepth }\end{array}$ & $\begin{array}{l}1.15 \\
1.03 \\
- \\
\end{array}$ & $\begin{array}{l}1.70 \\
1.50 \\
- \\
\end{array}$ & $\begin{array}{l}1.16 \\
1.79 \\
1.52 \\
\end{array}$ & $\begin{array}{l}1.39 \\
2.45 \\
1.83 \\
\end{array}$ & $\begin{array}{c}0.79 \\
1.60 \\
- \\
\end{array}$ & $\begin{array}{c}0.86 \\
1.82 \\
- \\
\end{array}$ & $\begin{array}{c}0.13 \\
0.21 \\
- \\
\end{array}$ & $\begin{array}{c}0.16 \\
0.27 \\
-\end{array}$ & $\begin{array}{c}0.49 \\
0.42 \\
- \\
\end{array}$ & $\begin{array}{c}0.90 \\
0.81 \\
- \\
\end{array}$ \\
\hline \multicolumn{11}{|c|}{ (c) April 14, 1995} \\
\hline $\begin{array}{l}\text { Surface } \\
\text { Bottom } \\
\text { Middepth }\end{array}$ & $\begin{array}{l}0.70 \\
0.87 \\
-\end{array}$ & $\begin{array}{l}0.78 \\
1.01 \\
-\end{array}$ & $\begin{array}{l}0.78 \\
1.13 \\
1.20\end{array}$ & $\begin{array}{l}1.01 \\
1.36 \\
1.47\end{array}$ & $\begin{array}{c}0.85 \\
1.44 \\
-\end{array}$ & $\begin{array}{c}0.93 \\
1.62 \\
-\end{array}$ & $\begin{array}{c}0.12 \\
0.15 \\
-\end{array}$ & $\begin{array}{l}0.13 \\
0.17 \\
-\end{array}$ & $\begin{array}{c}0.44 \\
0.32 \\
-\end{array}$ & $\begin{array}{l}0.80 \\
0.47 \\
-\end{array}$ \\
\hline
\end{tabular}
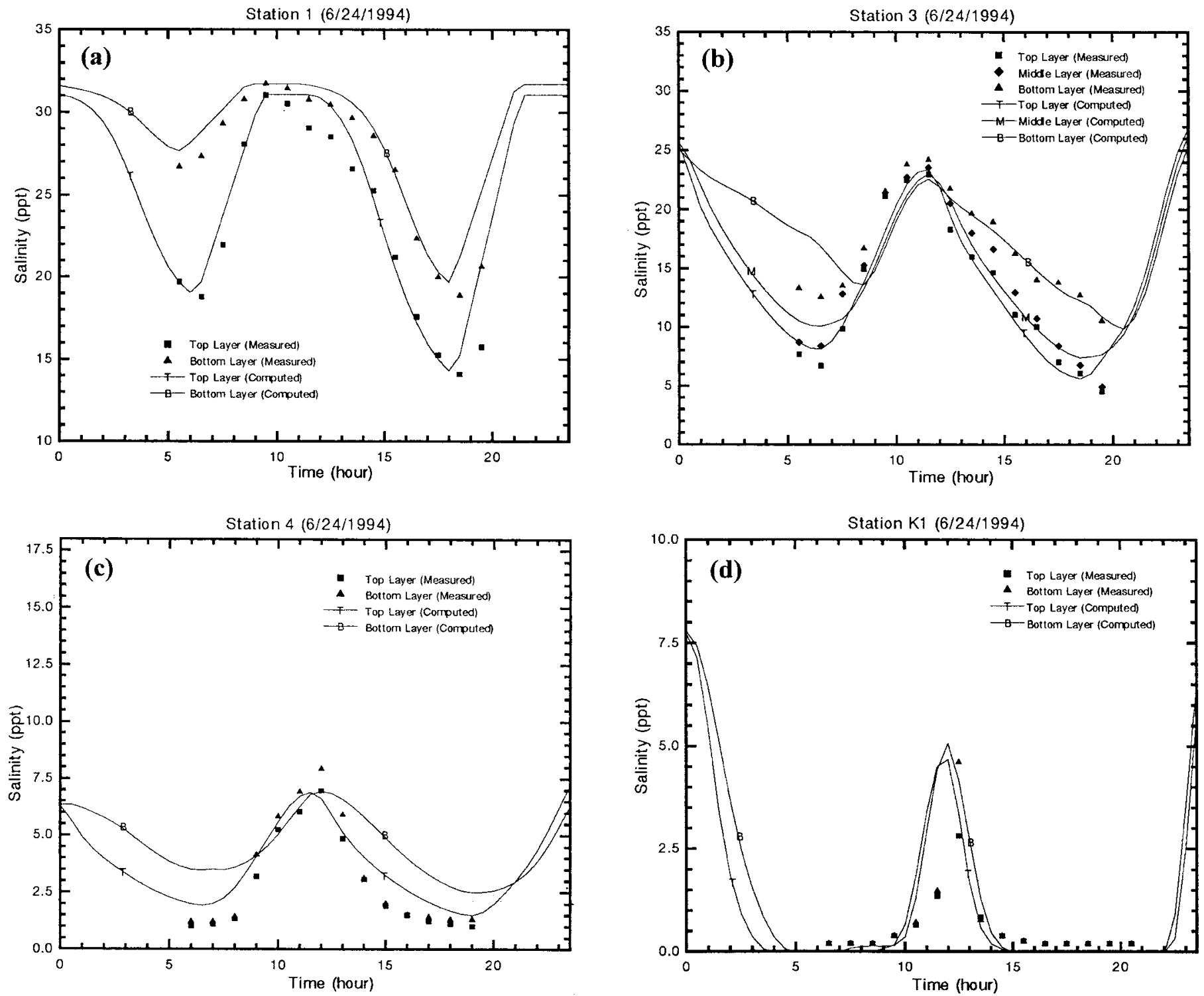

FIG. 10. Comparison of Computed Salinity with Time Series Data 
of the estuary has also been reported by Park and Kuo (1994). Because the wind was weak on June 24 , no wind was included in the model simulation for that period. The difference in the limits of salt intrusion between April 12 and June 24 reflects the higher freshwater discharge in the period prior to June 24. Tables 4( $a$ and $b$ ) list the mean absolute errors and root-meansquare errors that measure the differences between the computed and hourly measured data.

In the aforementioned calibration procedure, comparison of spatial distributions of salinity is used to guide the adjustment of calibration constants, because the spatial salinity distribution is the most important characteristic of an estuary. The longitudinal salinity gradient drives the estuarine (residual) circulation that is the dominant mechanism for long-term transport. The vertical salinity distribution characterizes the degree of stratification and controls the vertical mixing process. It is therefore important that a model be able to properly simulate the spatial salinity distribution. The calibration may be finetuned, to a lesser degree, by comparison of time series salinity data at a fixed point in space. Because the model salinity represents average values over some spatial domain while field data is at a single point, the pursuit of agreement between the two should not be overdone. Fig. 10 shows samples of the time series comparison at selected locations. Fig. 10(a) actually demonstrates the appropriateness of the method that the model used to generate the salinity boundary condition.

\section{MODEL VERIFICATION}

\section{Verification of Barotropic Flows}

Barotropic flows in estuaries include tidal flow, river discharge, topographic current, and the interaction among them. Since tidal flow dominates the real-time velocity in most estuaries, we have proposed calibrating the friction coefficient and correcting geometric data, if needed, with tidal information. There is little more to adjust to effect the simulation of overall barotropic flows, therefore we propose using the time series data of surface elevation and current velocity to verify this portion of the model.

In the present study, the model was verified by simulating the prototype conditions for the period of March 15 to September 30, 1994 without changing the values of the friction coefficient determined in calibration. Hourly measurements of water surface elevation at the river mouth and daily freshwater discharges upriver of tidal limits were used as boundary conditions. These conditions serve to investigate the model response to the interaction of tidal forcing and varying river discharges. Fig. 11 shows some segments of computed surface elevation, together with field data. It shows that upriver stations [Figs. 11(b and c)] have a more conspicuous response to pulse of high freshwater discharge than the downstream station [Fig. 11(a)]. Fig. 11(b and c) also show that, during the high flow periods, there are discrepancies between model predictions and field measurements at low tide. This may be attributed to the fact that daily mean discharges were used as input data, which cannot reflect the difference between two successive low tides. The model performance may be improved by specifying hourly discharges at the upstream boundaries if that is desirable. The linear interpolation of hourly surface elevation as a downstream boundary condition also contribute to model error. Assuming that the surface elevation varies sinusoidally with a period of $12 \mathrm{~h}$, the maximum error of $3.4 \%$ will occur when high or low tide happens exactly halfway between two data points. The average error should be smaller than half of that (i.e., $1.9 \mathrm{~cm}$ at the river mouth, which is smaller than the disagreement between model results and field data). The mean absolute errors of the differences between the measured hourly surface elevations and computed ones for the
Station 2
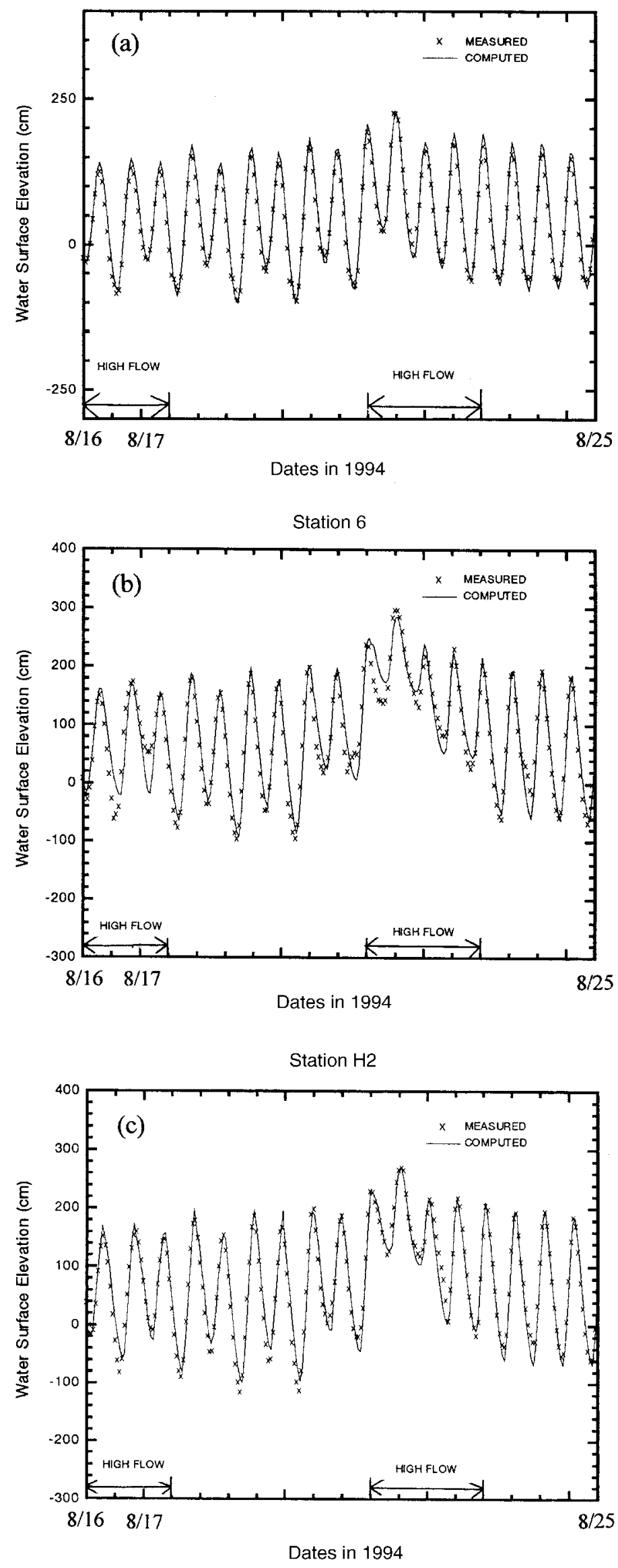

FIG. 11. Model Verification: Comparison of Computed and Measured Surface Elevations at: (a) Station 2-Tanshui River; (b) Station 6-Tahan Stream; (c) Station H2-Hsintien Stream 

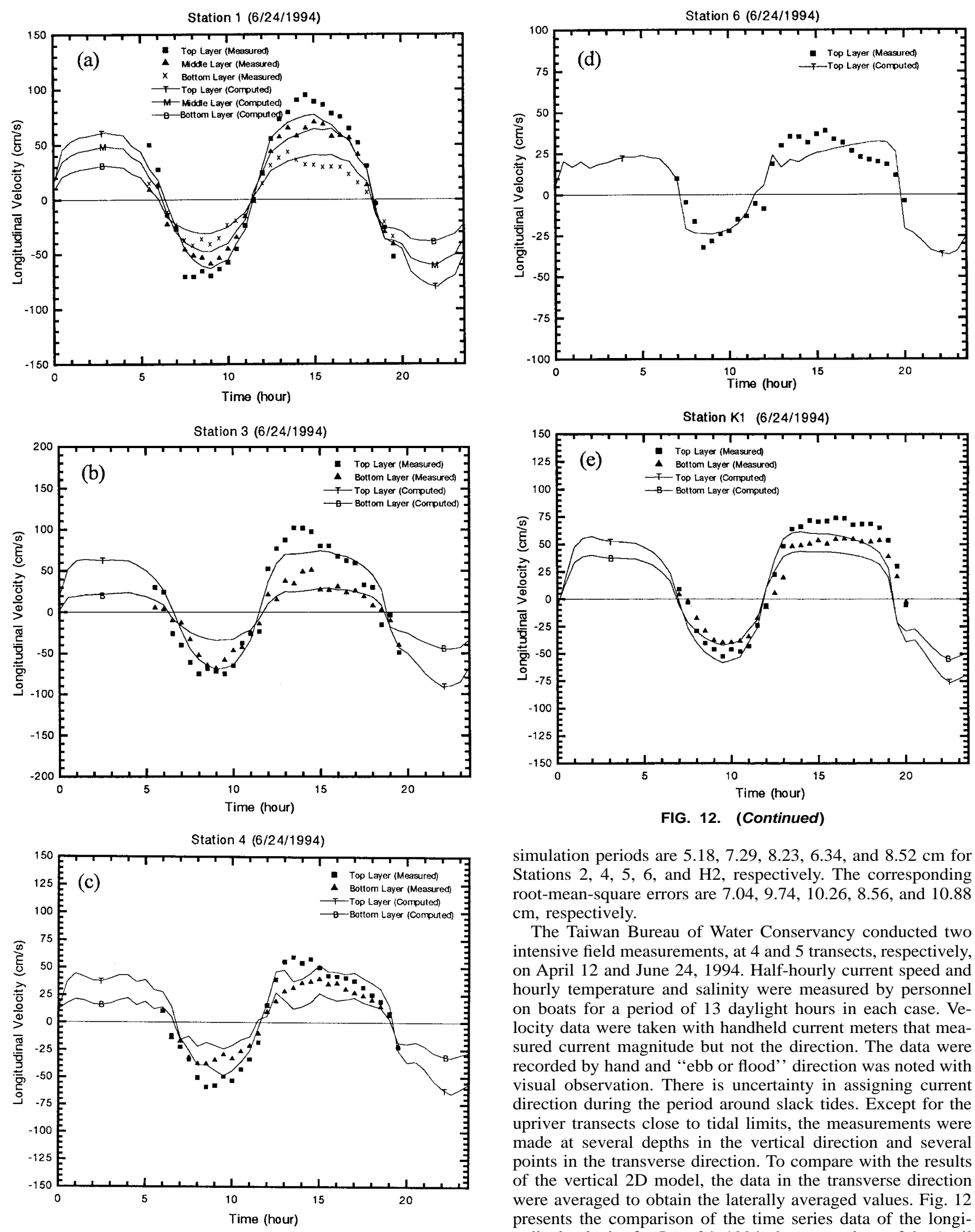

FIG. 12. Model Verification: Velocity Time Series Data at: (a) Station 1-Tanshui River Mouth; (b) Station 3-Tanshui River; (c) Station 4-Tanshui River; (d) Station 6-Tahan Stream; (e) Station K1-Keelung River (T Is Top Layer, M Is Middle Layer, B is Bottom Layer)

simulation periods are $5.18,7.29,8.23,6.34$, and $8.52 \mathrm{~cm}$ for Stations 2, 4, 5, 6, and $\mathrm{H} 2$, respectively. The corresponding root-mean-square errors are $7.04,9.74,10.26,8.56$, and 10.88 $\mathrm{cm}$, respectively.

The Taiwan Bureau of Water Conservancy conducted two intensive field measurements, at 4 and 5 transects, respectively, on April 12 and June 24, 1994. Half-hourly current speed and hourly temperature and salinity were measured by personnel on boats for a period of 13 daylight hours in each case. Velocity data were taken with handheld current meters that measured current magnitude but not the direction. The data were recorded by hand and "ebb or flood" direction was noted with visual observation. There is uncertainty in assigning current direction during the period around slack tides. Except for the upriver transects close to tidal limits, the measurements were made at several depths in the vertical direction and several points in the transverse direction. To compare with the results of the vertical 2D model, the data in the transverse direction were averaged to obtain the laterally averaged values. Fig. 12 presents the comparison of the time series data of the longitudinal velocity for June 24, 1994; the comparison of the April 12, 1994 data has similar characteristics. They verify that the flow is properly simulated by the model. The mean absolute errors of the differences between computed and measured data and the root-mean-square errors are presented in Table 5, they 
range from 8.0 to $35.0 \%$ of peak velocities at the corresponding stations. Fig. 12 indicates that there are discrepancies between model and field data when judging with point by point comparison. However, the model does properly simulate the temporal variation of velocity in terms of current amplitude and phase. The figure also shows that, where differences occur, the measured current velocities are higher than the computed ones in most instances. This is particularly apparent for the surface currents at downriver stations where the river is much wider. This may be attributable to the fact that the current meters used measured only the current speed but no direction. Therefore there is no information to reduce the prototype data to the longitudinal velocity components. It should be pointed out that there might be cases where the model-computed velocity is so different from the time series field data that it cannot be explained with the intrinsic differences between the two. Instead of readjusting the calibrated friction coefficient, we suggest that the model representation of the river geometry be carefully reexamined. The revision of local geometry may resolve the problem while not affecting the overall calibration.

\section{Verification of Residual Circulation}

In most estuaries, hidden under the visible oscillatory tidal current and, sometimes, the meteorologically forced current, are residual currents of much longer time scales. They include tidal residual and density currents. The tidal residual currents are induced by basin geometry and bathymetry; therefore they are basin or local specific and are not subjected to general theoretical analysis. The density current in estuaries is primarily forced by the longitudinal salinity gradient, and it has been a subject of systematic theoretical analyses. These currents are, in most cases, of an order of magnitude smaller than tidal current, and they are not discernible until the tidal current is filtered out. Therefore, verification of a numerical model for residual circulation is difficult. It requires a longer period of quality current meter records of which the tidal current may be filtered and meaningful residual velocity still remains.

As described in the previous section, all available velocity data in the Tanshui River system lasted for only $13 \mathrm{~h}$ in each survey. No time-varying residual velocity may be deduced through standard low-pass filtering. Instead, the 13-h time series data were fitted with the equation

$$
u(t)=\langle u\rangle+a \sin \omega t+b \cos \omega t
$$

by least-square error, where $\omega=$ angular velocity of the $M_{2}$ tide. The resulting coefficients $a$ and $b$ provide the amplitude and phase of $M_{2}$ constituent, respectively, and $\langle u\rangle$ is considered the residual velocity. $\langle u\rangle$ will then be compared with the tidal average velocity computed by the model for the corresponding day.

To provide additional verification of the model, a qualitative comparison of computed residual circulation with theoretical analysis was also conducted. Considering a laterally homogeneous and partially mixed estuaries of rectangular cross section, Hansen and Rattray (1965) derived an analytical model for the vertical profiles of Eulerian residual current and salinity for the central part of the estuary. Their model represents the residual circulation as the sum of three modes: (1) the river discharge mode; (2) the density current mode; and (3) the wind stress mode. When the wind stress is absent, the velocity profile depends on the value of one nondimensional number $\nu * \mathrm{Ra}$, where $v$ represents the diffusive fraction of the total upstream salt flux and $\mathrm{Ra}$ is an estuarine Rayleigh number. The sum of the river discharge mode and density current mode

TABLE 5. Mean Absolute Errors and Root-Mean-Square Errors of Differences between Computed and Measured Longitudinal Velocities

\begin{tabular}{|c|c|c|c|c|c|c|c|c|c|c|c|c|}
\hline \multirow[b]{3}{*}{$\begin{array}{l}\text { Layer } \\
\text { (1) }\end{array}$} & \multicolumn{12}{|c|}{ STATION } \\
\hline & \multicolumn{2}{|r|}{1} & \multicolumn{2}{|c|}{3} & \multicolumn{2}{|c|}{4} & \multicolumn{2}{|c|}{6} & \multicolumn{2}{|c|}{$\mathrm{H} 2$} & \multicolumn{2}{|c|}{ K1 } \\
\hline & $\begin{array}{c}\text { Mean } \\
\text { absolute } \\
\text { error } \\
(\mathrm{cm} / \mathrm{s}) \\
(2)\end{array}$ & \begin{tabular}{|c|} 
Root-mean- \\
square \\
error \\
$(\mathrm{cm} / \mathrm{s})$ \\
$(3)$
\end{tabular} & $\begin{array}{c}\text { Mean } \\
\text { absolute } \\
\text { error } \\
(\mathrm{cm} / \mathrm{s}) \\
(4)\end{array}$ & \begin{tabular}{|c|} 
Root-mean- \\
square \\
error \\
$(\mathrm{cm} / \mathrm{s})$ \\
$(5)$
\end{tabular} & $\begin{array}{c}\text { Mean } \\
\text { absolute } \\
\text { error } \\
(\mathrm{cm} / \mathrm{s}) \\
(6)\end{array}$ & \begin{tabular}{|c|} 
Root-mean- \\
square \\
error \\
$(\mathrm{cm} / \mathrm{s})$ \\
$(7)$
\end{tabular} & $\begin{array}{c}\text { Mean } \\
\text { absolute } \\
\text { error } \\
(\mathrm{cm} / \mathrm{s}) \\
(8)\end{array}$ & \begin{tabular}{|c|} 
Root-mean- \\
square \\
error \\
$(\mathrm{cm} / \mathrm{s})$ \\
$(9)$
\end{tabular} & $\begin{array}{c}\text { Mean } \\
\text { absolute } \\
\text { error } \\
(\mathrm{cm} / \mathrm{s}) \\
(10)\end{array}$ & \begin{tabular}{|c|} 
Root-mean- \\
square \\
error \\
$(\mathrm{cm} / \mathrm{s})$ \\
$(11)$
\end{tabular} & $\begin{array}{c}\text { Mean } \\
\text { absolute } \\
\text { error } \\
(\mathrm{cm} / \mathrm{s}) \\
(12)\end{array}$ & $\begin{array}{l}\text { Root-mean- } \\
\text { square error } \\
(\mathrm{cm} / \mathrm{s}) \\
(13)\end{array}$ \\
\hline \multicolumn{13}{|c|}{ (a) April 12, 1994} \\
\hline Surface & 11.74 & 14.09 & - & - & - & - & 3.47 & 4.56 & 6.21 & 7.60 & 5.55 & 7.43 \\
\hline Bottom & 8.85 & 10.97 & - & - & - & - & - & - & 4.12 & 5.36 & 5.75 & 7.40 \\
\hline Middepth & 8.60 & 10.56 & - & - & - & - & - & - & - & - & - & - \\
\hline \multicolumn{13}{|c|}{ (b) June 24,1994} \\
\hline Surface & 8.66 & 10.48 & 11.84 & 15.25 & 8.21 & \begin{tabular}{|l|}
10.01 \\
\end{tabular} & 7.05 & 8.45 & - & - & 10.88 & 14.28 \\
\hline Bottom & 5.66 & 6.56 & 8.71 & 12.06 & 9.00 & 10.69 & - & - & - & - & 9.13 & 11.75 \\
\hline Middepth & 4.98 & 5.69 & - & - & - & - & - & - & - & - & - & - \\
\hline
\end{tabular}

TABLE 6. Calculation of $v *$ Ra at Various Stations on April 12, and June 24, 1994

\begin{tabular}{|c|c|c|c|c|c|c|c|c|}
\hline \multirow[b]{2}{*}{$\begin{array}{l}\text { Parameter } \\
\text { (1) }\end{array}$} & \multicolumn{4}{|c|}{ April 12, 1994} & \multicolumn{4}{|c|}{ June 24, 1994} \\
\hline & $\begin{array}{c}2 \\
(2)\end{array}$ & $\begin{array}{c}4 \\
(3)\end{array}$ & $\begin{array}{l}\mathrm{K} 1 \\
(4)\end{array}$ & $\begin{array}{l}\mathrm{H} 1 \\
(5)\end{array}$ & $\begin{array}{c}2 \\
(6)\end{array}$ & $\begin{array}{c}4 \\
(7)\end{array}$ & $\begin{array}{l}\mathrm{K} 1 \\
(8)\end{array}$ & $\begin{array}{l}\mathrm{H} 1 \\
(9)\end{array}$ \\
\hline Depth $H(\mathrm{~m})$ & 11 & 8 & 7 & 6 & 11 & 8 & 7 & 6 \\
\hline Root-mean-square velocity $u_{t}(\mathrm{~m} / \mathrm{s})$ & 0.482 & 0.294 & 0.331 & 0.371 & 0.505 & 0.311 & 0.361 & 0.385 \\
\hline Vertical eddy viscosity $A_{z}\left(\times 10^{-4} \mathrm{~m}^{2} / \mathrm{s}\right)$ & 18.3 & 8.11 & 7.99 & 7.67 & 19.0 & 8.59 & 8.72 & 7.97 \\
\hline Freshwater velocity, $u_{f}(\mathrm{~m} / \mathrm{s})$ & 0.0155 & 0.0149 & 0.0279 & 0.0239 & 0.0477 & 0.0434 & 0.107 & 0.0889 \\
\hline $\begin{array}{l}\text { Longitudinal salinity gradient } \partial s / \partial x \\
\quad\left(\times 10^{-3} \mathrm{ppt} / \mathrm{m}\right)\end{array}$ & 1.01 & 0.77 & 1.04 & 0.98 & 1.30 & 0.70 & 0.90 & 0.80 \\
\hline$\Delta \rho / \rho\left(\times 10^{-3}\right)$ & 2.68 & 1.82 & 1.50 & 0.70 & 1.88 & 1.13 & 0.40 & 0.15 \\
\hline$F_{m}\left(\times 10^{-2}\right)$ & 2.94 & 3.97 & 8.68 & 11.7 & 10.6 & 14.6 & 64.9 & 94.7 \\
\hline$v * \mathrm{Ra}^{\mathrm{a}}$ & 349 & 238 & 118 & 84.8 & 139 & 70.6 & 24.2 & 17.9 \\
\hline$\nu * \mathrm{Ra}^{\mathrm{b}}$ & 229 & 180 & 100 & 79.6 & 86.2 & 67.8 & 22.1 & 16.7 \\
\hline
\end{tabular}


becomes bidirectional as $v * \mathrm{Ra}$ is $>30$, when the net circulation directs downriver in the upper layer and upriver in the lower layer. In a number of partially mixed estuaries this type of two-layered circulation is the dominant mechanism for longterm mass transport; thus its proper simulation is of the utmost importance.

Table 6 presents the values of the nondimensional number $\nu * \mathrm{Ra}$ and the parameters used to calculate them. The number $\nu * \mathrm{Ra}$ was calculated in two ways: (1) By the definitions of $v$ and $\mathrm{Ra}$; and (2) by its empirical relation to the densimetric Froude number as proposed by Hansen and Rattry (1966). The values at four representative stations on April 12 and June 24, 1994 were calculated, respectively, using the parameter values measured in prototype or computed by the numerical model. The table shows that there are differences between the corresponding values of $\nu * R a$ calculated with two different methods. However, the differences are not large enough to result in a significant difference in the velocity profiles they represent. Fig. 13 presents some theoretical profiles of the residual velocities, together with model results and field data. The model results are the model-calculated velocities averaged over two tidal cycles on corresponding days. There are quantitative discrepancies among model results, field data, and theoretical profiles; however, the figure shows that the strength of the computed and measured residual circulation decreases with decreasing $\nu * \mathrm{Ra}$, and the two-layered circulation ceases
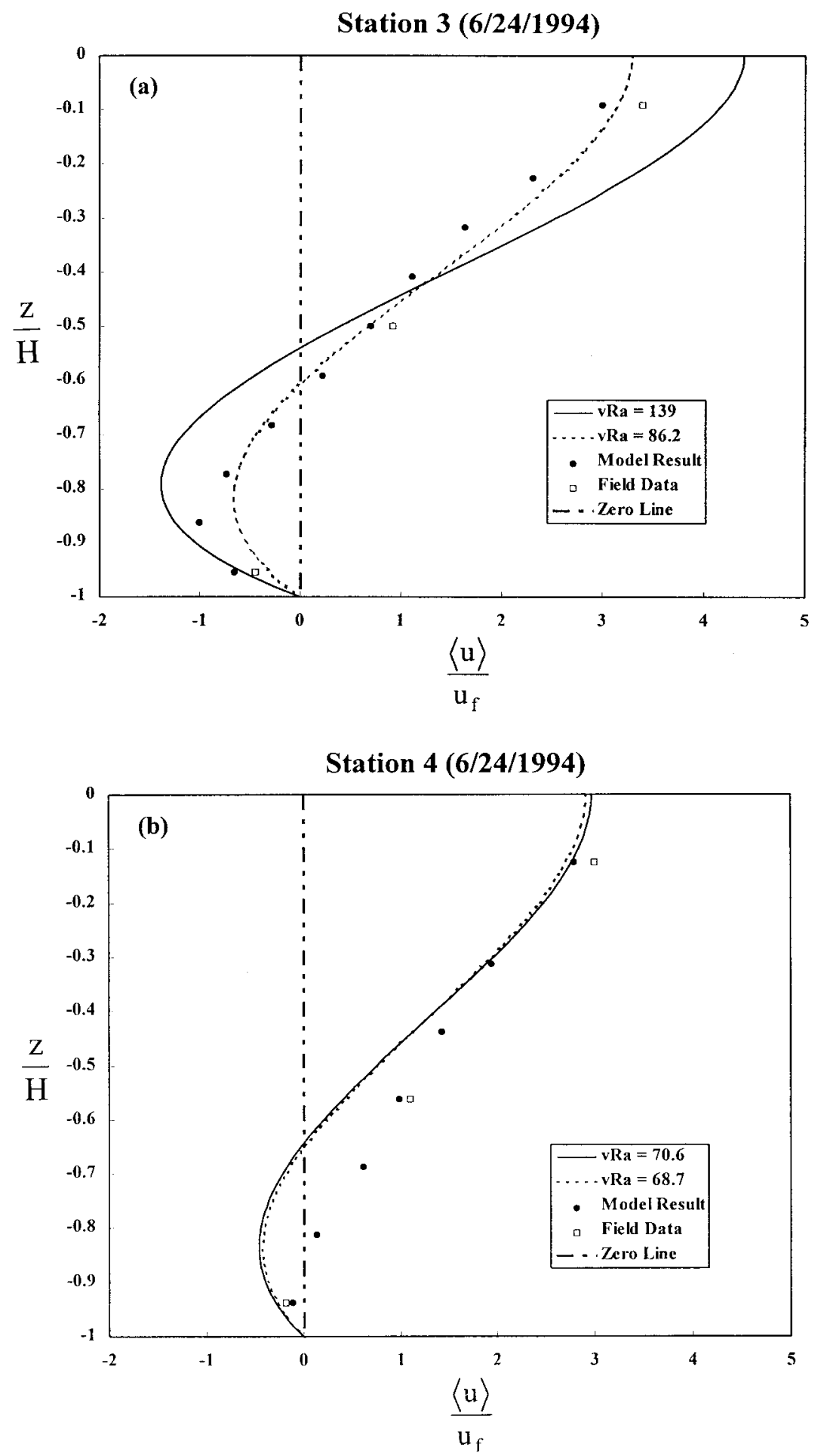

FIG. 13. Comparison of Computed and Measured Residual Velocity with Theoretical Velocity Profile 
Station K1 (6/24/1994)
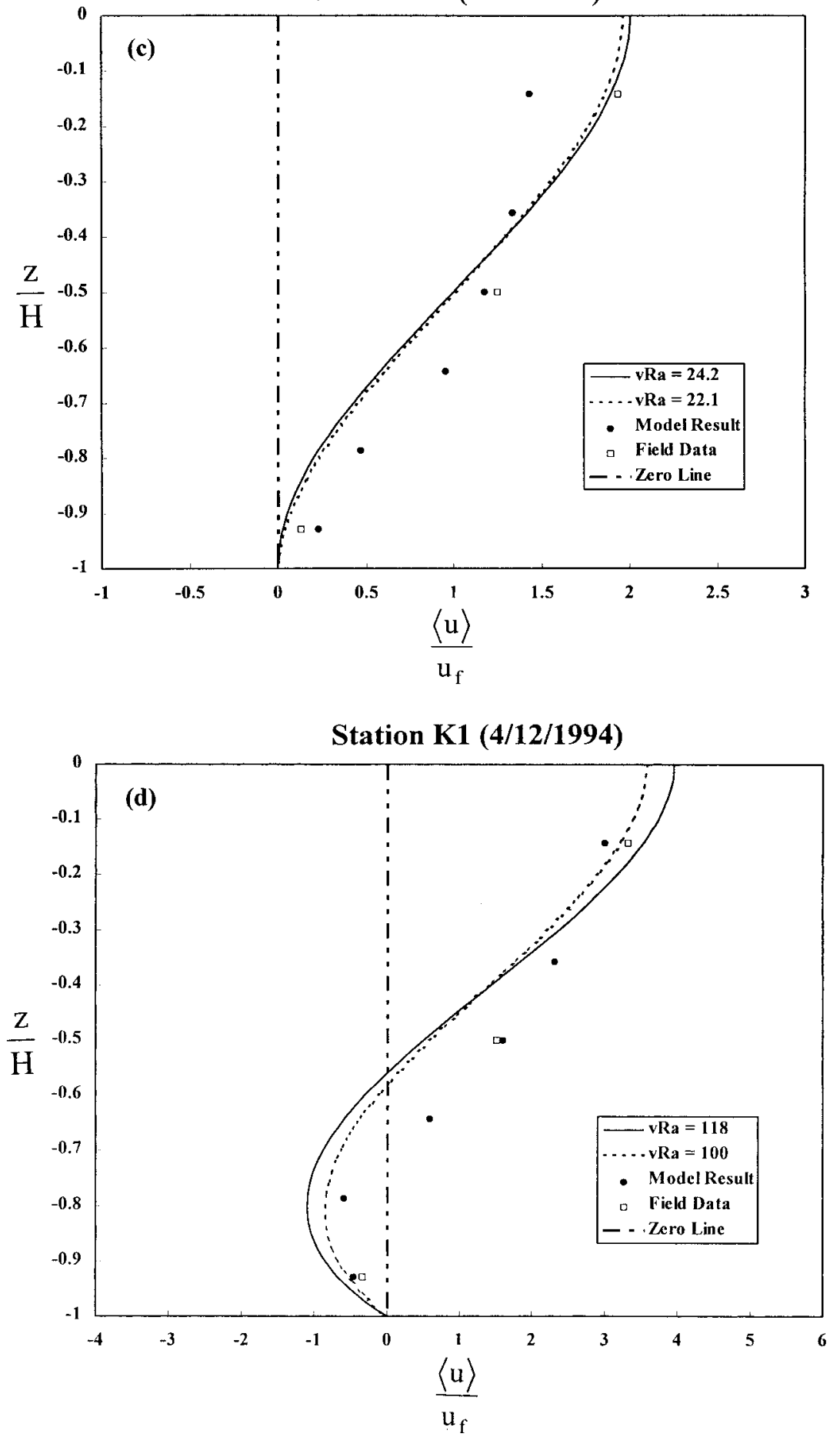

FIG. 13. (Continued)

to exist when $\nu *$ Ra drops below 30 . These are consistent, at least qualitatively, with the analytical model and render some verification for the numerical model.

\section{Verification of Salinity Distribution}

There are two types of physical processes involved in mass transport-advection and turbulent diffusion. The advective transport is achieved by current velocity, which includes tidal and residual currents. With both types of currents verified in the previous sections, the successful comparison of model simulation with another set of salinity data would serve to verify the model representation of diffusive transport. This was achieved with a model simulation of the prototype condition from March 15 to April 30, 1995. The data sources and procedure used to specify the boundary and initial conditions are similar to those of the calibration simulation.

An intensive survey was conducted by the Taiwan Bureau of Water Conservancy on April 14, 1995. Half-hourly measurements of velocity and hourly measurements of temperature and salinity were made continuously for 13 daylight hours at five stations. The hourly salinity data were averaged to obtain the tidal average salinity and shown in Fig. 14, together with the isohaline contours constructed from model outputs. The figure demonstrates that the model properly reproduces the salinity distribution, and thus its simulation of the mass transport processes is satisfactory. The graphical comparison of the time series data at fixed locations shows the same quality as 

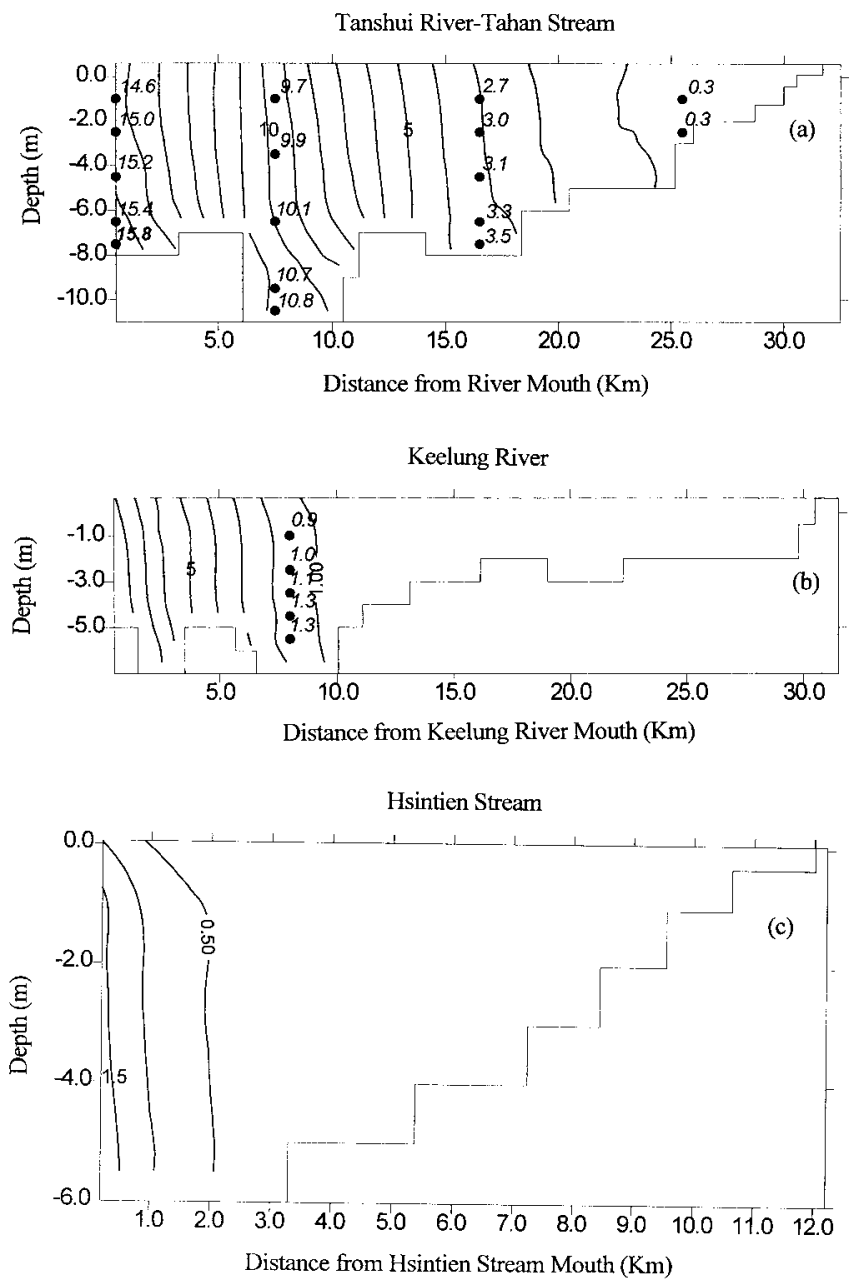

FIG. 14. Model Verification: Comparison of Computed (-) and Measured (•) Tidal Average Salinity on April 14, 1995: (a) Tanshui River-Tahan Stream; (b) Keelung River; (c) Hsintien Stream

that of the calibration run (Fig. 10). The mean absolute errors and root-mean-square errors of the differences between the computed and measured data are presented in Table 4(c); they range from 4.0 to $28.0 \%$ of the maximum salinity at corresponding stations.

\section{SUMMARY AND CONCLUSIONS}

A numerical hydrodynamic model is applied to the Tanshui River system in Taiwan, and a set of calibration and verification procedures is presented. The model is a vertical 2D model with added branching capability to handle multiple tributaries. The preliminary calibration of the friction coefficient uses a single constituent tide $M_{2}$ to reproduce the variation of mean tidal range along the river. The use of a single constituent tide expedites the extraction of tidal ranges from model outputs and thus the preliminary determination of the friction coefficient. The amplitude of the single constituent tide used as a forcing function at the river mouth should properly represent the total tidal energy. Half of the mean tidal range, not the amplitude of the tidal constituent from harmonic analysis, should be used. The model is then forced by a multiconstituent tide at the river mouth to fine tune the friction coefficient. The number of tidal constituents should be large enough to represent $>95 \%$ of tidal energy. The model is fine-tuned such that the amplitude and phase of the individual constituent as well as the average times of high and low tides be accurately reproduced. The fine-tuned calibration may first be achieved by aiming the proper simulation of the times of high and low tides. Once this is achieved, there is little more needed to be done for the amplitudes and phases of tidal constituents. The turbulent mixing processes are calibrated with the simulation of actual prototype conditions and comparisons of computed and observed salinity distributions.

The same simulation of prototype conditions used to calibrate mixing processes may also serve to verify the model simulation of barotropic flow and residual circulation. The barotropic flow is verified by comparing the time series data of measured water surface elevations and velocities with model outputs. One conspicuous feature to verify is the prototype response to high pulses of freshwater discharges. The longterm monitoring of surface elevations would easily capture such events. Ideally, there should be longer-term (longer than 3-5 days) velocity data to derive vertical profiles of residual current for comparison with model outputs. This requires high quality self-recording current meters and a permissible environment for unattended deployment. This is not the case in Taiwan at the present time, and an alternative approach is attempted. The snapshots of vertical profiles of computed and residual currents at various stations and different times are examined, together with residual velocities computed from single tidal cycle time series data. Their characteristic trends are compared with those predicted by the analytical model and found reasonably well behaved.

Finally, the overall performance of the model is verified with model simulation of another time period and compared with another data set. The successful simulation of water surface elevation is almost certain. The computed velocity can catch the temporal pattern of observed data. The agreement between observed and computed salinity distributions put the stamp of approval on the model.

\section{ACKNOWLEDGMENTS}

The project under which this study is conducted is supported by the National Science Council, R.O.C., under grant No. NSC-85-2211-E-002056. The prototype data were mostly provided by the Taiwan Bureau of Water Conservancy. The writers also would like to express their appreciation to the manuscript reviewers; through their comments this paper was substantially improved.

\section{APPENDIXI. REFERENCES}

Blumberg, A. F. (1977). "Numerical tidal model of Chesapeake Bay." $J$. Hydr. Div., ASCE, 103(1), 12701-12709.

Chen, C. L., and Lee, K. K. (1991). "Great Lakes river-estuary hydrodynamic finite element model.'” J. Hydr. Engrg., ASCE, 117(11), $1531-1550$.

Ditmars, J. D., Adams, E. E., Bedford, K. W., and Ford, D. E. (1987). "Performance evaluation of surface water transport and dispersion models." J. Hydr. Engrg., ASCE, 113(8), 961-980.

Hansen, D. V., and Rattry, M., Jr. (1965). "Gravitational circulation in straits and estuaries." J. Marine Res., 23, 104-122.

Hansen, D. V., and Rattry, M., Jr. (1966). "New dimensions in estuary classification." Limnol. Oceanog., 11, 319-326.

Hsu, M. H., Kuo, A. Y., Kuo, J. T., and Liu, W. C. (1996). "Study of tidal characteristics, estuarine circulation and salinity distribution in Tanshui River system.' Rep. to National Science Council, Taipei, Taiwan (in Chinese).

Ippen, A. T., and Harlman, D. R. F. (1966). "Tidal dynamics in estuaries." Estuary and coastline hydrodynamics, A. T. Ippen, ed., McGrawHill, New York, 493-545.

Johnson, B. H., Kim, K. W., Heath, R. E., Hsieh, B. B., and Butler, H. L. (1993). "Validation of three-dimensional hydrodynamic model of Chesapeake Bay."' J. Hydr. Engrg., ASCE, 119(1), 2-20.

Kuo, A. Y., and Park, K. (1995). "A framework for coupling shoals and shallow embayments with main channels in numerical modeling of coastal plain estuaries." Estuaries, 18(2), 341-350.

Muin, M., and Spaulding, M. L. (1996). "Two-dimensional boundaryfitted circulation model in spherical coordinates." J. Hydr. Engrg., ASCE, 122(9), 512-521.

Oey, L. Y., Mellor, G. L., and Hives, R. I. (1985). "Tidal modeling of the Hudson-Raritan Estuary." Estuarine, Coast. and Shelf Sci., 18, $511-527$. 
Park, K., and Kuo, A. Y. (1993). "A vertical two-dimensional model of estuarine hydrodynamics and water quality." Spec. Rep. App. Mar. Sci. and Ocean Eng. No. 321, Virginia Institute of Marine Science, Gloucester Point, Va., 47.

Park, K., and Kuo, A. Y. (1994). "Numerical modeling of advection and diffusion transport in the Rappahannock Estuary, Virginia.' Proc., 3rd Int. Conf. of Estuarine and Coast. Modeling, ASCE, New York, 461474.

Pritchard, D. W. (1960). "The movement and mixing of contaminants in tidal estuaries.' Waste disposal in the marine environment, E. A. Pearson, ed., Pergamon, Tarrytown, N.Y., 512-525.

Wang, J. D., Blumberg, A. F., Butler, H. L., and Hamilton, P. (1990). "Transport prediction in partially stratified tidal water." J. Hydr. Engrg., ASCE, 116(3), 380-396.

\section{APPENDIX II. NOTATION}

The following symbols are used in this paper:

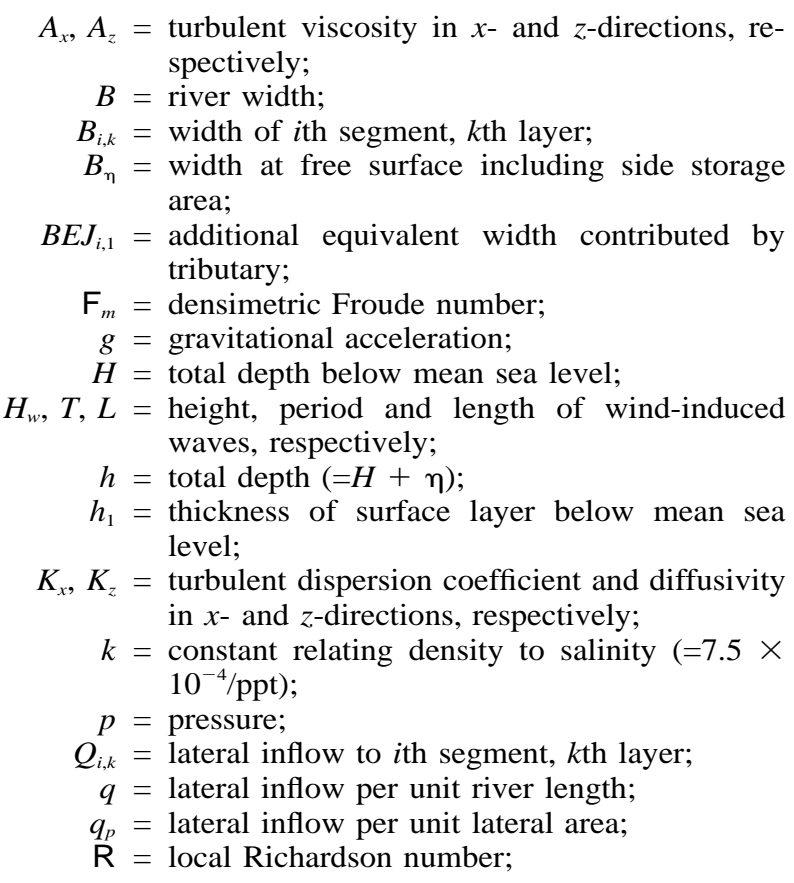

$\mathrm{Ra}=$ estuarine Rayleigh number;

$S_{0}=$ source and sink of salt due to exchange with side storage area;

$S T B_{i}=$ equivalent width of side storage area in $i$ th segment;

$s$ = laterally averaged salinity;

$T B, T \eta, T h, T u=$ width, surface elevation, layer thickness, and longitudinal velocity in tributaries, respectively;

$T w, T s=$ vertical velocity and salinity in tributaries, respectively;

$t=$ time;

$u=$ laterally averaged velocity in $x$-direction;

$\langle u\rangle=$ tidally averaged velocity component in $x$-direction;

$u_{f}=$ freshwater velocity;

$u_{i, k, 1}=$ longitudinal velocity at old time level;

$u_{t}=$ root-mean-square tidal current speed;

$w=$ laterally averaged velocity in $z$-direction;

$w_{i, k, 1}=$ vertical velocity at bottom of $i$ th segment, $k$ th layer at old time level;

$x=$ distance seaward along river axis;

$Z=$ depth below water surface;

$z=$ distance upward in vertical direction;

$\alpha, \beta, \alpha_{w}=$ constants;

$\Delta \rho=$ density difference between surface and bottom layers;

$\Delta t=$ time step;

$\Delta x=$ segment length;

$\eta=$ position of free surface above mean sea level;

$\eta_{i, 2}, \eta_{i, 1}=$ surface elevations of $i$ th segment at new and old time levels, respectively;

$v=$ diffusive fraction of total upstream salt flux;

$\rho=$ water density;

$\rho_{0}=$ freshwater density; and

$\partial s / \partial x=$ longitudinal salinity gradient.

\section{Subscripts}

$i=$ segment at mainstem;

$k=k$ th layer;

$m=$ segment at tributary; and

$N=$ bottom layer. 